\title{
Nutrient dynamics in tropical rivers, lagoons, and coastal ecosystems of eastern Hainan Island, South China Sea
}

\author{
R. H. Li ${ }^{1}$, S. M. Liu ${ }^{1}$, Y. W. Li ${ }^{1,3}$, G. L. Zhang ${ }^{1}$, J. L. Ren ${ }^{1}$, and J. Zhang ${ }^{2}$ \\ ${ }^{1}$ Key Laboratory of Marine Chemistry Theory and Technology, Ministry of Education, Ocean University of China, Qingdao \\ colobrative innovation center of marine science and technology, Qingdao 266100, China \\ ${ }^{2}$ State Key Laboratory of Estuarine and Coastal Research, East China Normal University, Shanghai 200062, China \\ ${ }^{3}$ now at: College of Chemistry and Chemical Engineering, Taishan University, Tai' an 271000, China
}

Correspondence to: S. M. Liu (sumeiliu@ouc.edu.cn)

Received: 10 April 2013 - Published in Biogeosciences Discuss.: 5 June 2013

Revised: 8 December 2013 - Accepted: 10 December 2013 - Published: 30 January 2014

\begin{abstract}
Nutrient dynamics based on field observations made along the eastern Hainan Island during the period 2006-2009 were investigated to understand nutrient biogeochemical processes, and to provide an overview of human perturbations of coastal ecosystems in this tropical region. The rivers showed seasonal variations in nutrient concentrations, with enrichment of dissolved inorganic nitrogen and dissolved silicate, and depletion of $\mathrm{PO}_{4}^{3-}$. High riverine concentrations of nitrate mainly originated from agricultural fertilizer inputs. The DIN : $\mathrm{PO}_{4}^{3-}$ ratios ranged from 37 to 1063, suggesting preferential depletion of $\mathrm{PO}_{4}^{3-}$ relative to nitrogen in rivers. Chemical weathering in the drainage area might explain the high levels of dissolved silicate. Aquaculture ponds contained high concentrations of $\mathrm{NH}_{4}^{+}$and dissolved organic nitrogen. The particulate phosphorus concentrations in the study area were lower than those reported for estuaries worldwide. The particulate silicate levels in rivers and lagoons were lower than the global average level. $\mathrm{Nu}$ trient biogeochemistry in coastal areas was affected by human activities (e.g., aquaculture, agriculture), and by natural phenomena including typhoons. The nutrient concentrations in coastal waters were low because of dispersion of land-derived nutrients in the sea. Nutrient budgets were built based on a steady-state box model, which showed that riverine fluxes are magnified by estuarine processes (e.g., regeneration, desorption) in estuaries and Laoyehai Lagoon, but not in Xiaohai Lagoon. Riverine and groundwater inputs were the major sources of nutrients to Xiaohai and Laoyehai lagoons, respectively, and riverine inputs and aquaculture effluents were the major sources for the eastern coast
\end{abstract}

of Hainan Island. Nutrient inputs to the coastal ecosystem increased with typhoon-induced runoff of rainwater, elucidating the important influence of typhoons on small tropical rivers.

\section{Introduction}

Estuaries and coastal areas are regions of high population density and intense human activities. The comprise approximately $7 \%$ of the surface area of the world's ocean, while accounting for $30 \%$ of the total net oceanic primary production (Alongi, 1998; Gattuso et al., 1998; Dürr et al., 2011). The rapid increase of human activities has increased nutrient transport from land to sea in the past decades, resulting in environmental deterioration and changes to biogeochemical processes (Seitzing et al., 2005; Halpern et al., 2008; $\mathrm{Qu}$ and Kroeze, 2010). Tropical estuaries are the most biogeochemically active zones, and are more easily affected by anthropogenic nutrient loading than estuaries at higher latitudes (Yule et al., 2010; Smith et al., 2012). This is particularly the case for the tropical South and Southeast Asia rivers and coastal region, which have been extensively modified by human activities, and for catchments, which have been degraded as a consequence of rapid economic development and population growth (Jennerjahn et al., 2008; Yule et al., 2010). These systems are highly sensitive to natural environmental changes and human activities, including land use, geomorphologic evolution (Jia et al., 2012) and deforestation (Meunier et al., 2011). However, the nutrient characteristics and 
Table 1. Length, drainage area and annual average freshwater discharge of rivers of the eastern Hainan Island. Wenchanghe (WC) and Wenjiaohe (WJ), in the city of Wenchang; Wanquanhe (WQ), Jiuqujiang (JQJ) and Longgunhe (LG), in the city of Qionghai; Longtouhe (LT), Longweihe (LW) and Taiyanghe (TY), in the city of Wanning (Wang, 2002; Zhang et al., 2006).

\begin{tabular}{llrrr}
\hline Source & $\begin{array}{r}\text { Length } \\
(\mathrm{km})\end{array}$ & $\begin{array}{r}\text { Drainage Area } \\
\left(\mathrm{km}^{2}\right)\end{array}$ & $\begin{array}{r}\text { Discharge } \\
\left(\mathrm{m}^{3} \mathrm{~s}^{-1}\right)\end{array}$ \\
\hline WC & Douniu (town) & 37.1 & 380.9 & 9.1 \\
WJ & Pokou (village) & 56.0 & 522.0 & 11.6 \\
WQ & Wuzhi Mountains & 163.0 & 3693.0 & 163.9 \\
JQJ & Wangtianlang & 50.0 & 279.8 & 10.2 \\
LG & Xianggen Ridge & 38.6 & 145.7 & 6.0 \\
LT & Huangzhu Ridge & 42.2 & 140.1 & 6.1 \\
LW & Liulian Ridge & 61.6 & 197.0 & 7.5 \\
TY & Changsha Ridge & 82.5 & 576.3 & 23.8 \\
\hline
\end{tabular}

the processing of nutrients in tropical rivers and estuaries are poorly studied relative to those in temperate zones (Thomas et al., 2004; Smith et al., 2012).

The South China Sea (SCS) is an oligotrophic ocean located in the tropical to subtropical western Pacific Ocean. It has a total area of approximately $3.5 \times 10^{6} \mathrm{~km}^{2}$, and is one of the largest marginal seas in the world (Xu et al., 2008). The SCS is dominated by the East Asian monsoon (Su, 2004), with southwesterly winds prevailing in summer and autumn, and northeasterly winds in winter and spring (Chen and Chen, 2006). Summer upwelling and cyclonic eddies driven by the southwest monsoon are among the most important physical processes in the coastal waters of the northern SCS (Li et al., 2010). With a water discharge of $482.1 \times 10^{9} \mathrm{~m}^{3} \mathrm{yr}^{-1}$, Pearl River, is the largest river that discharges directly into the northern SCS (Liu et al., 2009). Harmful algal blooms have frequently occurred off Pearl River and enormous economic losses in aquaculture have been caused because of the increasing load of nutrients in recent decades as a result of economic growth and urban development (Wang et al., 2008). Many estuary eutrophication studies have focused on this large estuary system (Yin, 2002; $\mathrm{Xu}$ et al., 2008; Qiu et al., 2010), but nutrient conditions in smaller rivers and well-flushed estuaries are less well known, particularly along the eastern coast of Hainan Island (Fig. 1).

Our study focused on the eastern coast of Hainan Island, which is a tropical coastal environment affected by natural processes (e.g., monsoons, upwelling and river discharge) and human activities (e.g., agriculture, aquaculture and tourism) (Chai et al., 2001; Jing et al., 2009; Su et al., 2011a). The study area represents a diverse range of geomorphological settings and biological habitat types. It has a number of small mountainous rivers (Table 1), dense mangrove vegetation, and a shallow shelf with coral reefs and seagrass beds (Roder et al., 2013). Agriculture is the major land use on the island. Terrigenous materials are transported

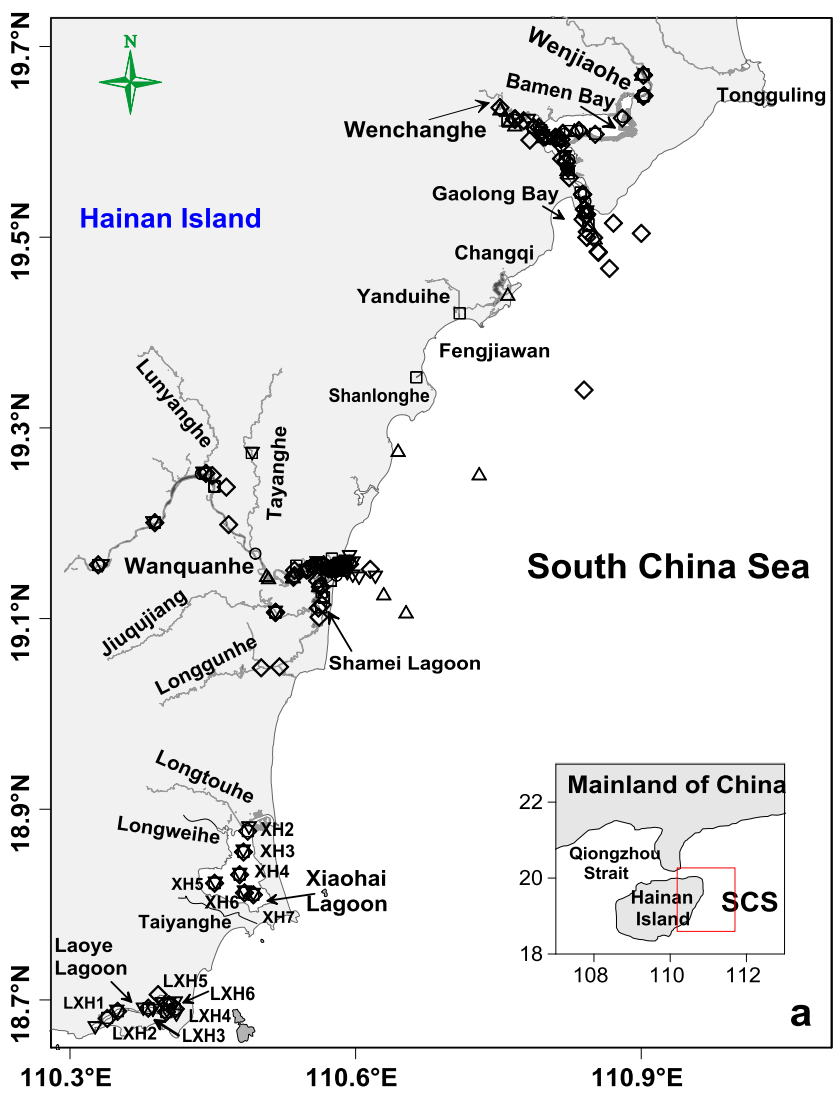

Fig. 1. Location map of the study area and stations for the sampling cruises along the eastern Hainan Island during 2006-2009. (a): Sampling stations for the cruises in rivers and estuaries, and for shrimp ponds, groundwater and lagoons of the South China Sea in December $2006(\triangle)$, August $2007(\circ)$, June-August $2008(\diamond)$, March-April $2009(\square)$, and June-August $2009(\nabla)$. Anchor stations sampled in August 2007 (T2-3) and June 2008 (T2-2). The inset at the lower right (a) is the location map. (b): Sampling stations in coastal waters of the northern South China Sea (SCS) in August 2007 (०), June-August $2008(\diamond)$, August 2008 (४), March-April $2009(\square)$ and June-August $2009(\nabla)$ (16: anchor station).

from freshwater to brackish water, and disperse in mangrove ecotone and the shallow estuary. Economic development has increased nutrient loads and influenced nutrient cycling in coastal region, resulting in accelerated degeneration of the coastal ecosystems and the occurrence of eutrophication (Pan et al., 2007). Over recent decades many coastal mangrove areas have been lost because of aquaculture, tourism, residential and golf course developments. The mangrove forests of Hainan Island covered approximately 10000 ha in 1972, but by 2003 approximately $57 \%$ of these forests had been lost through deforestation and reclamation for aquaculture ponds (Zhou, 2004). The study coastal lagoons are subject to intense human impacts that have caused significant changes in hydrology, increased anthropogenic nutrient delivery, and changed the coral reef ecosystems (Roder et al., 2013; Zhang 


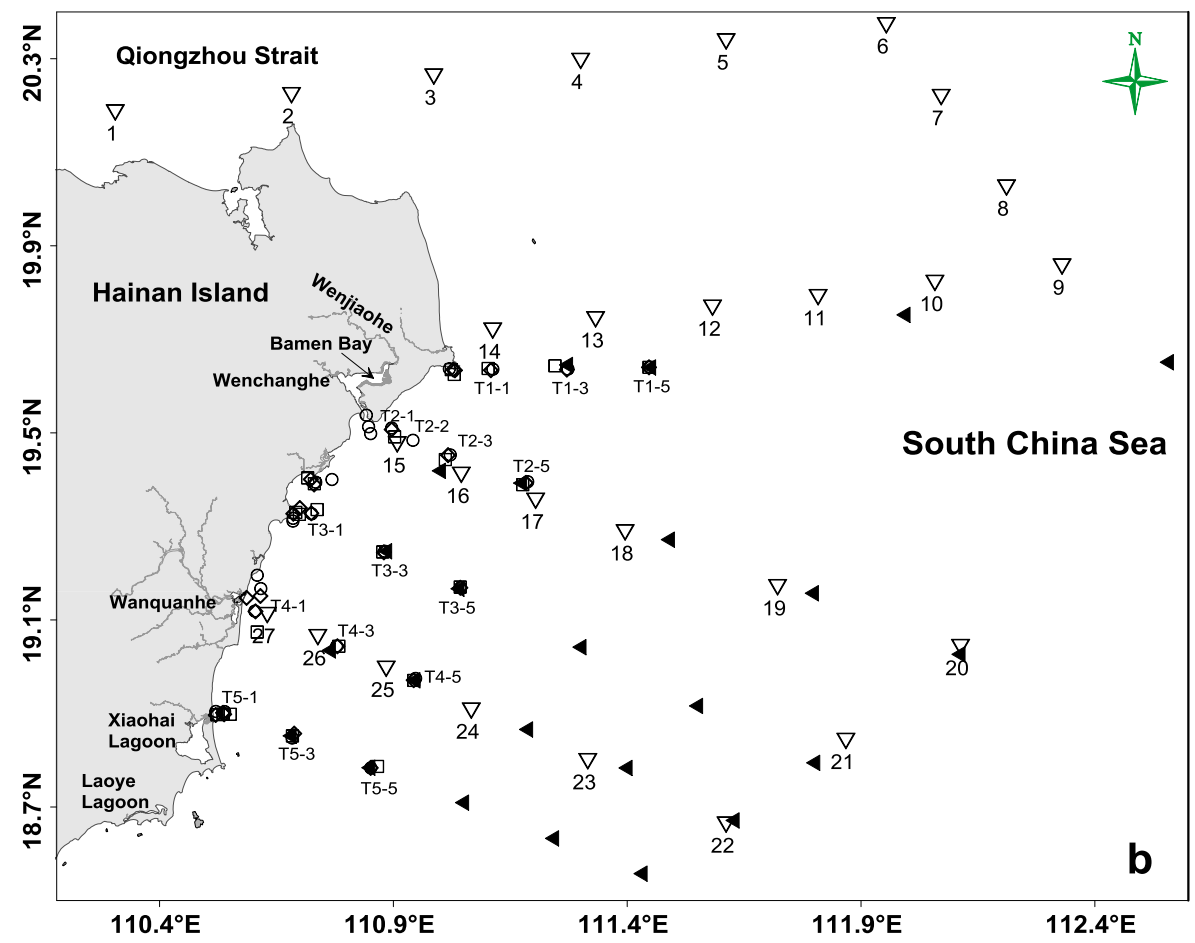

Fig. 1. Continued.

et al., 2013). Rivers discharging into the SCS along the eastern Hainan Island are all relatively small (Table 1), and are more readily affected by human activities and environmental change than large river systems. In addition, Hainan Island is frequently affected by tropical storms and typhoons between August and September (Zhang et al., 2010); which bring large amounts of rainfall and lead to a rapid hydrological response (Mao et al., 2006). Nutrient loads and phytoplankton biomass can increase in response to typhoonrelated floods. Typhoons play an important role in enhancing oceanic primary productivity in oligotrophic ocean waters (Ning et al., 2004), especially in typhoon-dominated seas (Zheng and Tang, 2007; Zhao et al., 2009). Under the combined effects of human activities and natural events, coastal ecosystems of tropical region are vulnerable to these effects, which can accelerate their degradation. Hence, it is essential to understand sources of nutrients and biogeochemical cycling processes in tropical coastal region.

Six cruises were carried out along the eastern Hainan Island during the period 2006-2009. Here we present the results of studies of nutrient dynamics in water and suspended matter from tropical rivers, their associated lagoons, and adjacent coast of the eastern Hainan Island. The aim of this study was to characterize spatiotemporal variations in the distribution of nutrients in this tropical shallow coastal region in order to delineate nutrient dynamics and biogeochemistry under the influence of natural and anthropogenic factors, and to assess the impact of human activities on the ecosystems of the receiving coastal waters.

\section{Materials and methods}

\subsection{Study area}

Hainan Island is located at the southernmost tip of China; it is the largest island in the SCS, and is separated from mainland China by Qiongzhou Strait. It has a coastline length of $1550 \mathrm{~km}$, covers a land area of $35.4 \times 10^{3} \mathrm{~km}^{2}$, and in 2011 had a population of nearly 9.08 million (Hainan Statistical Yearbook, 2012). The area is characterized by a tropical monsoonal climate (Zeng and Zeng, 1989), with northerly winds prevailing in winter and southerly winds dominating in summer (Wang, 2002). Annual rainfall is $1600-1800 \mathrm{~mm}$, and approximately $80 \%$ of this falls during the wet season, i.e., from May to October (Mao et al., 2006). The coast is subject to mixed semidiurnal microtides with typical tidal ranges $<1 \mathrm{~m}$, and approximately $1.6 \mathrm{~m}$ during neap and spring tides (Krumme et al., 2012). Coastal upwelling occurs along the eastern coast of Hainan Island, driven by strong southwest monsoon and topography (Jing et al., 2009; Su and Pohlmann, 2009). The upwelling commences in April and ends in October, and extends from $30 \mathrm{~m}$ water depth to $10 \mathrm{~km}$ offshore (Li et al., 2011a).

The study area, along the eastern Hainan Island from Tongguling to Laoyehai (LYH) Lagoon (Fig. 1), has a narrow 
continental shelf from water depth 0 to $100 \mathrm{~m}$ (Tang et al., 2003), and is open to the sea. Four lagoons along the coast were formed in a transgression process during the Quaternary period (Wang et al., 2006). These shallow lagoons are subject to freshwater and marine interactions; they are connected to the open sea via narrow channels, and are semiclosed by sand barriers. Base on tidal amplitude, Bamen Bay is considered to be a lagoonal inlet. The Wenchanghe (WC) and Wenjiaohe (WJ) rivers empty into the kidney-shaped Bamen Bay, which connects to the sea through an approximately $9.0 \mathrm{~km}$ long narrow natural channel (Wang et al., 2006). An outer semi-closed bay, named Gaolong Bay, was formed through local hydrodynamics and sediment transport. The Wenchanghe/Wenjiaohe Estuary (WWE) is characterized by mixed semi-diurnal microtides, having a mean tidal amplitude $<2$ m (Unger et al., 2013). Riverine input, groundwater discharge and aquaculture effluents have been shown to be the major source of nutrients entering the estuary (Liu et al., 2011).

The Wanquanhe (WQ) is the third largest river on Hainan Island. It empties directly into the SCS, where a dynamic typical lagoon-tidal-inlet-barrier system has formed (Zhu et al., 2005). Approximately $3.9 \times 10^{6} \mathrm{t} \mathrm{yr}^{-1}$ sediment is loaded to the estuary (Wang et al., 2006). The estuary is comprised of two semi-closed parts: the WQ tidal inlet and Shamei Lagoon. The Tayanghe (Ty) and Lunyanghe (LY) rivers flow through cultivated land and enter the WQ from the north. The Jiuqujiang (JQJ) and Longgunhe (LG) empty into Shamei Lagoon from the west and south, respectively (Wang, 2002). The Wanquanhe Estuary (WQE) has an irregular diurnal microtidal regime with a mean range of approximately $0.7-$ $0.8 \mathrm{~m}$ (Zhu et al., 2005). The water residence time is estimated to be 0.2-4.7 days. Riverine input is the major source of nutrients to the estuary ( $\mathrm{Li}$ et al., 2013). The salinity of Shamei Lagoon has been reduced to $<1$ because of aquaculture activities, which have reduced the tidal hydrodynamics (Ge et al., 2004; Jia et al., 2012).

Xiaohai (XH) Lagoon is a typical well-developed tidalinlet-lagoon system, and is the largest lagoon on Hainan Island. The approximate surface area of the gourd-shaped lagoon was $49 \mathrm{~km}^{2}$ in 1960 , and has decreased to $44 \mathrm{~km}^{2}$ (Wang et al., 2006); it now has a mean water depth of $1.5 \mathrm{~m}$ because of land reclamation and aquaculture activities (Gong et al., 2008). Eight small rivers empty into XH Lagoon with annual mean total discharge of $26.5 \mathrm{~m}^{3} \mathrm{~s}^{-1}$. The lagoon connects to the sea through a narrow tidal channel, in which approximately 5000 fishing cages have been installed since 1986 (Gong et al., 2008). The lagoon is a significant fishing port on the eastern coast of Hainan Island. Aquaculture activities have expanded enormously in recent decades, and these have resulted in deterioration of the tidal flushing efficiency. The water residence time in the lagoon has increased from 45 to 71 days (Gong et al., 2008).

LYH Lagoon has a surface area of approximately $26 \mathrm{~km}^{2}$ (Ji et al., 2013) and is comprised of two parts: (i) the inner bay, which is little affected by the tide and contains many fish ponds; and (ii) the approximately $8 \mathrm{~km}$ tidal channel that connects to the sea and contains a large number of fish farming cages. The width of the tidal channel has narrowed from $425 \mathrm{~m}$, which it was in the $1960 \mathrm{~s}$, to $75 \mathrm{~m}$ at present (Wang et al., 2006). Three rivers contribute a very small discharge (approximately $0.4 \mathrm{~m} \mathrm{~s}^{-1}$ ) directly into LYH Lagoon (Ji et al., 2013).

\subsection{Sampling}

Six sampling cruises were carried out along the coast of eastern Hainan Island: on 7-15 December 2006 (winter), 1228 August 2007 (summer), 23 July-13 August 2008 (summer), 25 August-6 September 2008 (summer), 27 March14 April 2009 (spring), and 23 July-8 August 2009 (summer). A broad range of water bodies were included in the various sampling stations (Fig. 1). We considered the cruises in August 2007, July-August 2008 and July-August 2009 to have occurred in the wet season, and those in December 2006 and March-April 2009 to have occurred in dry season. Anchor stations were established off Gaolong Bay, and were monitored for $25 \mathrm{~h}$ in August 2007, in July 2008, and in July 2009. During sampling cruises in July 2008 and April 2009, water samples were collected from Changqi Bay, which is the second-largest aquaculture production area on Hainan Island. To assess human impacts on coral reefs, coastal water samples within the coral reef region were collected from a small boat. Water samples were also collected from shrimp ponds and from wells (groundwater) located within the study area.

Water samples from rivers and shrimp ponds were collected from the river/pond bank or from a small boat, using 11 acid-cleaned polyethylene bottles attached to the end of a fiberglass reinforced plastic pole. For the estuaries and lagoons, water sampling was based on the salinity gradient. Surface water samples were collected in acid-cleaned polyethylene bottles during spring tides. Seawater samples were collected from various depths in $10 \mathrm{~L}$ Niskin bottles, with sampling based on CTD ( $\mathrm{SBE}^{\circledR} 25$, Seabird, USA) readings. A WTM Multiline F/Set3 multiparameter probe was used to measure water temperature and salinity in both rivers and estuaries. Coastal water temperature and salinity were measured using the CTD profiler. Samples for dissolved nutrients-testing were filtered through acid precleaned $0.45 \mu \mathrm{m}$ pore size cellulose acetate filters. The filtrates were immediately fixed by the addition of saturated $\mathrm{HgCl}_{2}$ solution and taken back to laboratory for analysis. The filters were dried at $45^{\circ} \mathrm{C}$ and weighed to determine the mass of suspended particulate matter (SPM), particulate inorganic phosphorus (PIP), and particulate organic phosphorus (POP). Samples for particulate biogenic silicon (PBSi) and lithogenic silicon (LSi) were filtered through $47 \mathrm{~mm}$ polycarbonate membrane filters $(0.4 \mu \mathrm{m}$ pore size $)$ that had been dried at $45^{\circ} \mathrm{C}$. 


\subsection{Chemical analysis}

Dissolved nutrient concentrations were determined using a Skalar SANplus AutoAnalyzer (Liu et al., 2011). Total dissolved nitrogen (TDN) and phosphorus (TDP) were measured according to the methods of Grasshoff et al. (1999). The analytical precision for $\mathrm{NO}_{3}^{-}, \mathrm{NO}_{2}^{-}, \mathrm{NH}_{4}^{+}, \mathrm{PO}_{4}^{3-}$, dissolved silicate (DSi), TDN and TDP was $<5 \%$. The concentration of dissolved inorganic nitrogen (DIN) is the sum of $\mathrm{NO}_{3}^{-}, \mathrm{NO}_{2}^{-}$and $\mathrm{NH}_{4}^{+}$. The concentrations of dissolved organic nitrogen (DON) and phosphorus (DOP) were estimated by subtracting DIN from TDN and $\mathrm{PO}_{4}^{3-}$ from TDP, respectively.

Particulate phosphorus (PP) in SPM was measured using the methods of Aspila et al. (1976). The extracted $\mathrm{PO}_{4}^{3-}$ was measured by spectrophotometry. The analytical precision of PP, PIP, and POP was $<5 \%$ (Li et al., 2011b). The concentration of POP was estimated by subtracting PIP from PP. The concentration of total phosphorus (TP) was calculated as the sum of PP and TDP. PBSi and LSi in SPM were measured based on the methods of Ragueneau et al. (2005). The extracted DSi was measured by spectrophotometry. The analytical precision of PBSi and LSi measurements was $7 \%$ $(n=7)$ and $8 \%(n=7)$, respectively (Li et al., 2011b).

\subsection{Lagoon nutrient budgets}

Dissolved and particulate nutrient budgets for the coastal lagoon systems in our study were constructed based on a box model designed by Land-Ocean Interactions in the Coastal Zone (LOICZ) (Gordon et al., 1996). This model has been widely used to construct dissolved and particulate nutrient budgets in estuarine and coastal ecosystems in order to understand the internal biogeochemical processes and external nutrient inputs of the system being studied (Fang, 2004; Savchuk, 2005; Liu et al., 2009). Hence, both dissolved and particulate nutrient budgets in our study area were estimated based on the box model. In our model, we assumed that the study systems were in a steady state, and each estuary/lagoon was treated as a single box that mixed well, except that a twobox model was used as a function of different water residence time between Shamei Lagoon and the WQ tidal inlet in the WQE.

Briefly, the water mass balance (Eq. 1), salinity balance (Eq. 2), and the non-conservative fluxes of nutrient elements (Eq. 3) based on nutrient concentrations and water budgets were estimated as follows:

$V_{\mathrm{R}}=V_{\text {in }}-V_{\text {out }}=-V_{\mathrm{Q}}-V_{\mathrm{P}}-V_{\mathrm{G}}-V_{\mathrm{W}}+V_{\mathrm{E}}$.

$V_{\mathrm{X}}\left(S_{1}-S_{2}\right)=S_{\mathrm{R}} V_{\mathrm{R}}$.

$\Delta Y=\sum$ outflux $-\sum$ influx $=V_{\mathrm{R}} C_{\mathrm{R}}+V_{\mathrm{X}} C_{\mathrm{X}}-V_{\mathrm{Q}} C_{\mathrm{Q}}-V_{\mathrm{P}} C_{\mathrm{P}}$. where $V_{\mathrm{R}}$ is the residual flow, and $V_{\mathrm{Q}}, V_{\mathrm{P}}, V_{\mathrm{G}}, V_{\mathrm{W}}, V_{\mathrm{E}}, V_{\mathrm{in}}$, $V_{\text {out }}$ and $V_{\mathrm{X}}$ are the river discharge, precipitation, groundwater, wastewater, evaporation, inflow of water to the system of interest, outflow of water from the system of interest, and the mixing flow between the two systems, respectively. The volume of aquaculture effluents directly discharged into the system of interest is not considered, as data is limited. We assumed that the salinity of fresh water $\left(V_{\mathrm{Q}}, V_{\mathrm{P}}\right.$ and $\left.V_{\mathrm{E}}\right)$ was 0. In addition, $S_{\mathrm{R}}=\left(S_{1}+S_{2}\right) / 2 . S_{1}$ and $S_{2}$ in Eq. (2) refer to the average salinity of the system of interest and the adjacent system, respectively. Hence, the total water exchange time $(\tau)$ of the system of interest was estimated from the ratio of $V_{\mathrm{S}}$ to $\left(V_{\mathrm{R}}+V_{\mathrm{X}}\right)$, where $V_{\mathrm{S}}$ is the volume of the system. In Eq. (3), $C_{\mathrm{Q}}, C_{\mathrm{P}}, C_{\mathrm{R}}$ and $C_{\mathrm{X}}$ are the the average concentrations of nutrients in the river discharge, the precipitation, the residual flow and the mixing flow, respectively. $C_{\mathrm{R}}$ and $C_{\mathrm{X}}$ equate to $\left(C_{1}+C_{2}\right) / 2$ and $\left(C_{1}-C_{2}\right)$, respectively. $C_{1}$ and $C_{2}$ are the average concentrations of nutrients in the system of interest and the adjacent system, respectively. A negative or positive sign for $\Delta Y$ indicates that the system of interest was a sink or a source, respectively.

\section{Results}

\subsection{Hydrographic conditions}

Surface water temperature was lower in the dry season (23.3$\left.28.7^{\circ} \mathrm{C}\right)$ than in the wet season $\left(27.0-33.6^{\circ} \mathrm{C}\right)$, reflecting the seasonality of this tropical system. For XH Lagoon, the salinity varied from 1.8 to 10.6 during the study period. The salinity varied greatly in LYH Lagoon (9.1-33.2) with salinity gradients increasing towards the mouth of the lagoon (Fig. 2b). The low salinity in the inner part of LYH Lagoon (9.1-16) and XH Lagoon indicate that these carried a mixture of fish-farming and freshwater discharge.

SPM concentrations also showed clear seasonal variation. SPM concentration ranged from $7.85 \mathrm{mg} \mathrm{L}^{-1}$ to $46.3 \mathrm{mg} \mathrm{L}^{-1}$ in the WC (mean $20.7 \mathrm{mg} \mathrm{L}^{-1}$ ), and a peak $\left(46.3 \mathrm{mg} \mathrm{L}^{-1}\right.$ ) was observed following the typhoon event in 2008. SPM concentrations in the WQ were generally similar except during the 2009 spring cruise, when SPM concentrations ranged from $7.47 \mathrm{mg} \mathrm{L}^{-1}$ to $71.1 \mathrm{mg} \mathrm{L}^{-1}$ due to large river discharge (maximum $278 \mathrm{~m}^{3} \mathrm{~s}^{-1}$ ) associated with the first rain event in spring 2009. SPM concentrations in XH Lagoon were higher during the wet season than during the dry season, with means of $23.6 \pm 15.2 \mathrm{mg} \mathrm{L}^{-1}$ and $9.94 \pm 3.23 \mathrm{mg} \mathrm{L}^{-1}$, respectively. In LYH Lagoon SPM concentrations ranged from 2.08 to $20.6 \mathrm{mg} \mathrm{L}^{-1}$ (mean $8.64 \mathrm{mg} \mathrm{L}^{-1}$ ), and were lower than in XH Lagoon. The SPM levels in coastal water (mean $3.47 \mathrm{mg} \mathrm{L}^{-1}$ ) were lower than in rivers and the lagoons, indicating effective removal from the lagoons and coastal region.

A number of different water masses were observable in coastal water. The surface water temperature in coastal increased from south to north in August 2007 and 2008, and 
a
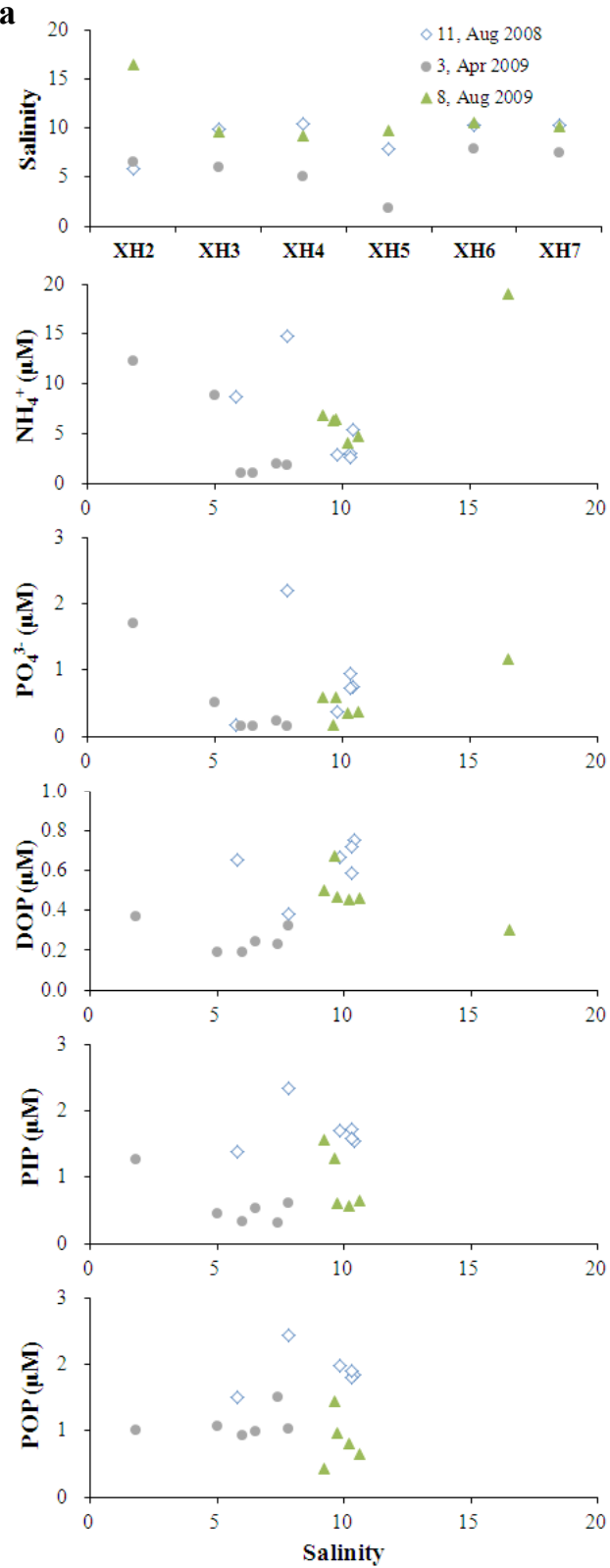
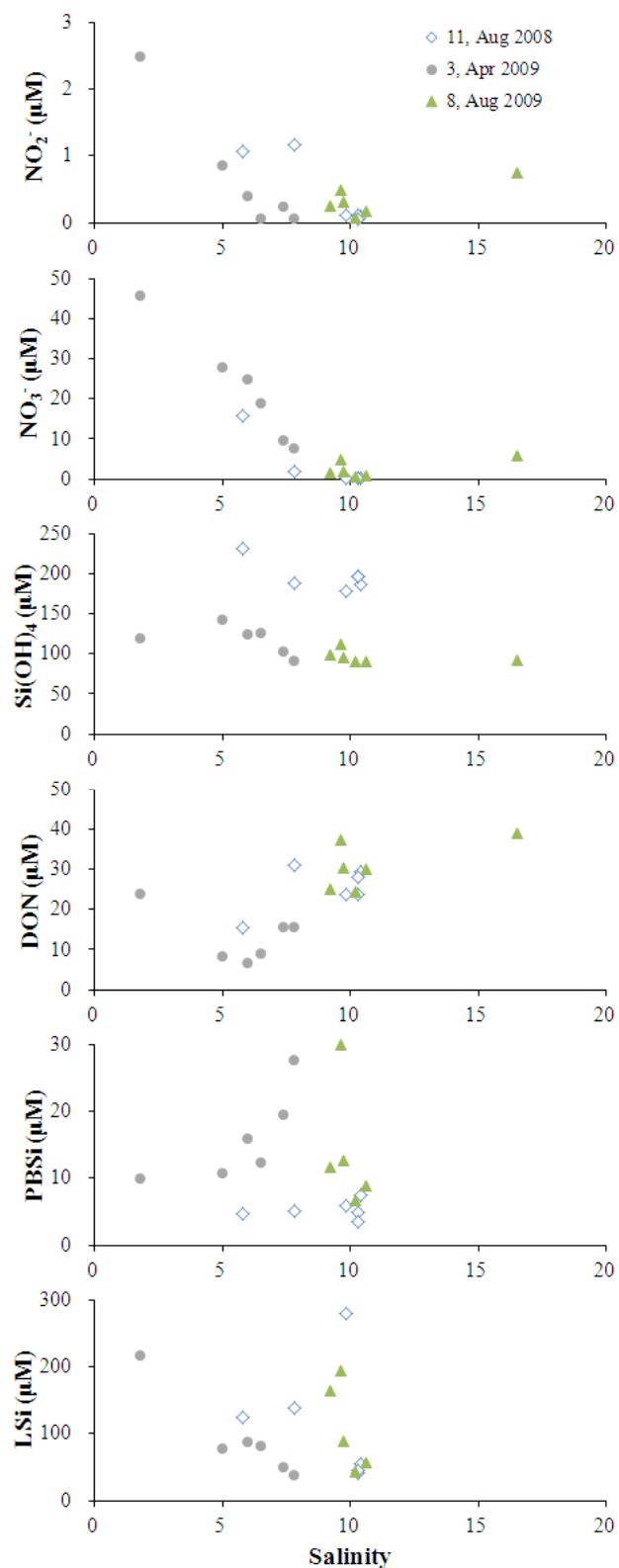

Fig. 2. Spatial distributions of salinity and nutrients $(\mu \mathrm{M})$ as a function of salinity in surface waters of the Xiaohai (a) and Laoyehai (b) lagoons during the study period.

increased from north to south in April 2009 (Fig. 3). The cruise in August 2007 took place following a typhoon event, which may account for the lower temperatures found relative to those in July-August 2008, and may have led to low salinity outside the lagoons. Surface salinity ranged from 22.0 to 34.2 in summer and 29.7-32.9 in spring. In addition, surface salinity gradually increased from nearshore to offshore regions, and the salinity isohalines were parallel to the coastline (Fig. 3). A cyclonic eddy appeared at $18.5^{\circ} \mathrm{N}$ with a cold center near Bamen Bay (Su et al., 2011a), which may have led to the high temperature/low salinity center observed dur- ing the August-September 2008 cruise (Fig. 3d). Thermohaline stratification was found near the surface at all stations during the 2007 and 2008 summer cruises. The temperature isopleth in summer gradually increased from the bottom waters to the surface (Fig. S1 a, b).

\subsection{Nutrients in rivers}

The nutrient concentrations in rivers along the eastern coast of Hainan Island varied greatly during the study period (Table 2). Rivers were generally enriched with DIN relative to $\mathrm{PO}_{4}^{3-}$, with the DIN : $\mathrm{PO}_{4}^{3-}$ ratios ranging between 37 and 

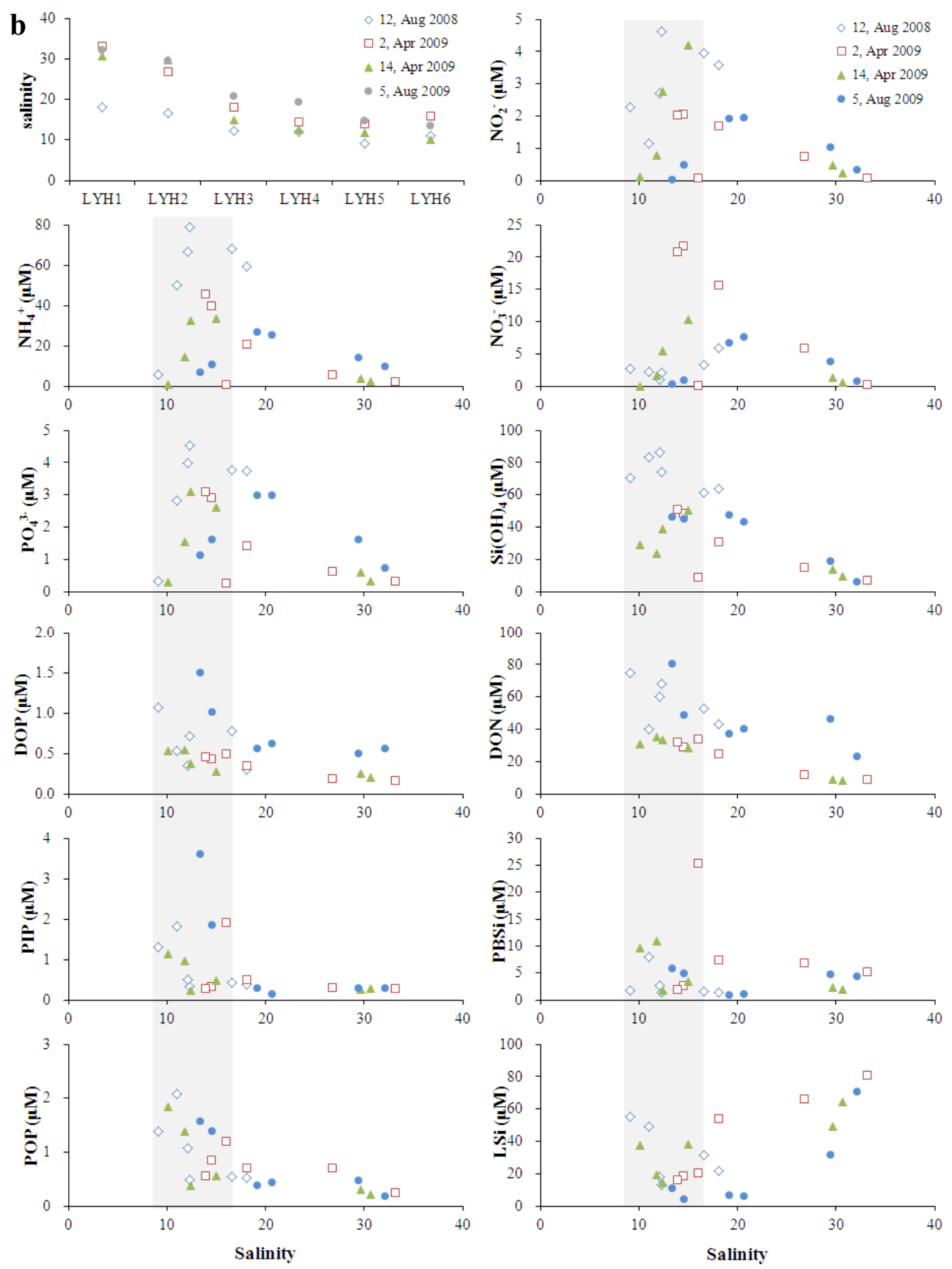

Fig. 2. Continued.

1063 (Table 2). DIN was dominated by $\mathrm{NO}_{3}^{-}$, which accounted for $56-98 \%$ of DIN during the wet and dry seasons. The concentrations of $\mathrm{NO}_{2}^{-}$in rivers (generally $>2.0 \mu \mathrm{M}$ ) at Wenchang were higher than those at Qionghai city, with the exception of the JQJ in August 2009 (Table 2). The $\mathrm{PO}_{4}^{3-}$ concentrations were $<1.0 \mu \mathrm{M}$ during all cruises except for the JQJ in August 2009. The concentrations of DOP in rivers during the wet season represented $52-97 \%$ of TDP, and were higher than in the dry season, while the DON concentrations in the dry season were higher than in the wet season (Table 2). The average concentration of DSi (mean $191 \mu \mathrm{M}$ ) was high in rivers in our study area, especially in the WQ (mean $322 \mu \mathrm{M})$.

Particulate nutrient investigations were only carried out in the WC, WJ and WQ rivers. The PP concentrations varied from $0.43 \mu \mathrm{M}$ to $4.50 \mu \mathrm{M}$, and the mean concentrations $(1.48 \mu \mathrm{M})$ accounted for 35,59 and $31 \%$ of $\mathrm{TP}$ in the $\mathrm{WC}, \mathrm{WJ}$ and WQ rivers, respectively. In addition, the PIP 
Table 2. Mean \pm SD for nutrient concentrations $\left(\mu \mathrm{mol} \mathrm{L}{ }^{-1}\right)$ and molar ratios in surface water of the Wenchanghe (WC), Wenjiaohe $(\mathrm{WJ})$, Wanquanhe (WQ), shrimp ponds and groundwater $(\mathrm{GW})$, and nutrient concentration $\left(\mu \mathrm{mol} \mathrm{L}^{-1}\right)$ in other small rivers along the eastern Hainan Island in different seasons during the investigation periods (wet season: May to October; dry season: November to April). LY: Lunyanghe; YD: Yanduihe; SL: Shanlonghe; Ty: Tayanghe; TY: Taiyanghe. n.a.: no data.

\begin{tabular}{|c|c|c|c|c|c|c|c|c|c|c|c|c|c|c|}
\hline & season & $\mathrm{NO}_{3}^{-}$ & $\mathrm{NO}_{2}^{-}$ & $\mathrm{NH}_{4}^{+}$ & DON & $\mathrm{PO}_{4}^{3-}$ & DOP & PIP & POP & $\mathrm{Si}(\mathrm{OH})_{4}$ & PBSi & $\mathrm{LSi}$ & DIN/DIP & $\mathrm{Si} / \mathrm{DIN}$ \\
\hline WC & dry & $69.5 \pm 29.4$ & $2.22 \pm 0.93$ & $10.4 \pm 5.79$ & $40.9 \pm 29.1$ & $0.55 \pm 0.48$ & $0.34 \pm 0.20$ & $1.22 \pm 0.37$ & $0.99 \pm 0.53$ & $167 \pm 18.4$ & $4.28 \pm 3.77$ & $69.8 \pm 44.4$ & $232 \pm 160$ & $2.3 \pm 0.9$ \\
\hline WC & wet & $65.4 \pm 2.61$ & $2.79 \pm 1.25$ & $31.9 \pm 22.3$ & $18.7 \pm 5.56$ & $0.66 \pm 0.36$ & $2.14 \pm 2.39$ & $1.34 \pm 0.21$ & $0.93 \pm 0.17$ & $151 \pm 25.6$ & $3.28 \pm 3.03$ & $159 \pm 178$ & $171 \pm 67$ & $1.6 \pm 0.3$ \\
\hline WJ & dry & $90.2 \pm 1.53$ & $2.86 \pm 0.10$ & $3.92 \pm 0.77$ & $59.3 \pm 1.78$ & $1.00 \pm 0.09$ & $0.50 \pm 0.26$ & $2.31 \pm 0.81$ & $1.38 \pm 0.21$ & $97.8 \pm 1.92$ & $20.4 \pm 4.52$ & $269 \pm 50.0$ & $97 \pm 7.9$ & $1.0 \pm 0.04$ \\
\hline WJ & wet & $23.8 \pm 3.10$ & $2.18 \pm 0.13$ & $7.72 \pm 0.56$ & $52.9 \pm 14.5$ & $0.35 \pm 0.13$ & $2.42 \pm 1.23$ & $1.25 \pm 0.10$ & $1.60 \pm 0.87$ & $118 \pm 6.43$ & $6.20 \pm 3.66$ & $89.3 \pm 37.9$ & $99 \pm 27$ & $4.7 \pm 2.2$ \\
\hline WQ & dry & $52.4 \pm 16.5$ & $1.02 \pm 0.42$ & $4.80 \pm 2.22$ & $13.5 \pm 11.6$ & $0.80 \pm 0.21$ & $0.77 \pm 0.41$ & $0.51 \pm 0.27$ & $0.54 \pm 0.26$ & $327 \pm 69.1$ & $7.64 \pm 3.16$ & $156 \pm 155$ & $79 \pm 30$ & $6.0 \pm 1.7$ \\
\hline WQ & wet & $39.3 \pm 13.7$ & $0.91 \pm 0.64$ & $5.81 \pm 3.97$ & $11.9 \pm 5.34$ & $0.57 \pm 0.34$ & $2.41 \pm 1.75$ & $0.47 \pm 0.29$ & $0.45 \pm 0.15$ & $317 \pm 29.0$ & $4.88 \pm 1.61$ & $61.7 \pm 30.1$ & $95 \pm 41$ & $7.9 \pm 3.1$ \\
\hline Shrimp & dry & $6.85 \pm 11.1$ & $32.2 \pm 95.4$ & $4.84 \pm 6.84$ & $39.4 \pm 21.7$ & $1.18 \pm 1.56$ & $0.61 \pm 0.40$ & n.a. & n.a. & $48.1 \pm 56.5$ & n.a. & n.a. & $40 \pm 70$ & $45 \pm 86$ \\
\hline Shrimp & wet & $9.67 \pm 4.91$ & $103 \pm 92.7$ & $93.7 \pm 77.6$ & $103 \pm 39.0$ & $6.17 \pm 5.43$ & $0.70 \pm 0.49$ & n.a. & n.a. & $54.6 \pm 29.4$ & n.a. & n.a. & $36 \pm 14$ & $2.2 \pm 3.6$ \\
\hline GW & dry & $592 \pm 434$ & $0.57 \pm 1.06$ & $3.63 \pm 4.42$ & $75.5 \pm 81.3$ & $13.1 \pm 31.4$ & $2.22 \pm 4.95$ & n.a. & n.a. & $330 \pm 157$ & n.a. & n.a. & $8430 \pm 15767$ & $6.6 \pm 19$ \\
\hline \multirow[t]{2}{*}{ GW } & wet & $446 \pm 490$ & $1.02 \pm 1.87$ & $7.07 \pm 13.4$ & $37.3 \pm 38.0$ & $2.09 \pm 5.84$ & $0.34 \pm 0.47$ & n.a. & n.a. & $333 \pm 164$ & n.a. & n.a. & $3277 \pm 8736$ & $9.0 \pm 19$ \\
\hline & date & $\mathrm{NO}_{3}^{-}$ & $\mathrm{NO}_{2}^{-}$ & $\mathrm{NH}_{4}^{+}$ & DON & $\mathrm{PO}_{4}^{3-}$ & DOP & $\mathrm{Si}(\mathrm{OH})_{4}$ & DIN/DIP & $\mathrm{Si} / \mathrm{DIN}$ & & & & \\
\hline SL & Mar, 2009 & 97.2 & 5.39 & 4.14 & 33.3 & 0.28 & 0.26 & 237 & 381 & 2.2 & & & & \\
\hline YD & Mar, 2009 & 144 & 2.63 & 2.28 & 30.9 & 0.14 & 0.38 & 210 & 1063 & 1.4 & & & & \\
\hline LY & Mar, 2009 & 122 & 5.42 & 5.55 & 35.6 & 0.60 & 0.33 & 214 & 218 & 1.6 & & & & \\
\hline Ty & Aug, 2009 & 57.3 & 1.20 & 9.77 & 54.6 & 0.75 & 0.81 & 195 & 91 & 2.9 & & & & \\
\hline$J Q J$ & Aug, 2008 & 35.6 & 0.95 & 7.44 & 20.9 & 0.55 & 1.67 & 101 & 143 & 1.3 & & & & \\
\hline JQJ & Mar, 2009 & 96.6 & 1.71 & 5.09 & 38.7 & 0.10 & 0.68 & 101 & 1034 & 1.0 & & & & \\
\hline$J Q J$ & Aug, 2009 & 70.2 & 2.89 & 6.89 & 50.4 & 2.16 & n.a. & 148 & 37 & 1.9 & & & & \\
\hline LG & Aug, 2008 & 55.7 & 0.62 & 8.30 & 20.3 & 0.38 & 2.66 & 195 & 170 & 3.0 & & & & \\
\hline LT & Aug, 2008 & 32.9 & 0.62 & 9.16 & 10.8 & 0.24 & 2.76 & 246 & 178 & 5.8 & & & & \\
\hline LW & Aug, 2008 & 35.1 & 0.98 & 8.01 & 6.25 & 0.11 & 2.34 & 180 & 401 & 4.1 & & & & \\
\hline TY & Mar, 2009 & 97.2 & 5.39 & 4.14 & 33.3 & 0.28 & 0.26 & 237 & 381 & 2.2 & & & & \\
\hline
\end{tabular}

concentrations accounted for 58, 53 and $49 \%$ of PP in the WC, WJ and WQ rivers, respectively. The mean PIP and POP concentrations in the $\mathrm{WJ}$ and $\mathrm{WQ}$ rivers were comparable during the dry and wet seasons, and the average PIP concentration in the WC was higher in the dry season than in the wet season (Table 2). The PIP and POP concentrations in the WC and WJ rivers were a factor of 1.9-4.6 higher than in the WQ. The PBSi and LSi concentrations were highly variable during the dry season, and higher than in the wet season except for the WC (Table 2). The concentrations of PBSi in rivers ranged from 0.91 to $25.2 \mu \mathrm{M}$ (mean $6.71 \mu \mathrm{M}$ ). The PBSi concentrations accounted for 2, 10 and $2 \%$ of PBSi plus silicic acid concentration in the $\mathrm{WC}, \mathrm{WJ}$ and $\mathrm{WQ}$ rivers, respectively. The DSi concentrations in the WQ were higher than in the WC and $\mathrm{WJ}$ rivers, while, the mean concentrations of $\mathrm{PBSi}$ and LSi in the $\mathrm{WJ}$ were higher than in other two rivers (Table 2).

Molar DIN : $\mathrm{PO}_{4}^{3-}$ in rivers (Table 2) were significantly higher than the Redfield ratio, indicating that $\mathrm{P}$ may limit primary production despite high nitrate values. DSi to DIN molar ratios were higher than or comparable to 1 , which is typical of tropical rivers generally enriched with dissolved silicate.

\subsection{Nutrients in shrimp ponds and groundwater}

The nutrient concentrations in shrimp ponds varied considerably, as indicated by the large standard deviation (Table 2). The mean nutrient concentrations, particularly those of $\mathrm{NH}_{4}^{+}$ and DON, were higher in the wet season than in the dry season (Table 2). Average $\mathrm{NH}_{4}^{+}$concentrations were high, ranging $4.8 \mu \mathrm{M}$ in the dry season to $93.7 \mu \mathrm{M}$ in the wet season, and accounted for $48-54 \%$ of DIN. The $\mathrm{NO}_{2}^{-}$concentrations in shrimp ponds ranged from 0.06 to $287 \mu \mathrm{M}$, but were typically $<0.5 \mu \mathrm{M}$; the exception was one site in Changqi Bay, where the concentration reached $287 \mu \mathrm{M}$. The concentrations of $\mathrm{PO}_{4}^{3-}$ in shrimp ponds ranged from 0.18 to $11.1 \mu \mathrm{M}$ (mean $6.17 \mu \mathrm{M}$; Table 2). The $\mathrm{DIN}: \mathrm{PO}_{4}^{3-}$ ratios ranged from 0.6 216. DON represented $21-98 \%$ of TDN, and DOP was 8 $69 \%$ of TDP during the study. In the wet season all nutrient concentrations (with the exceptions of $\mathrm{NO}_{3}^{-}$, DOP, and DSi) were higher in ponds than in rivers, while in the dry season, ponds had lower concentrations than rivers except $\mathrm{PO}_{4}^{3-}$ and DSi (Table 2) prior to the grow-out period.

The concentrations of nutrients in groundwater $(\mathrm{GW})$ ranged over two orders of magnitude during the investigation, and the DIN : $\mathrm{PO}_{4}^{3-}$ molar ratios were very high (Table 2). The mean nutrient concentrations were higher in $\mathrm{GW}$ than other water bodies (rivers and ponds). In particular, the mean concentrations of $\mathrm{NO}_{3}^{-}$ranged from $446 \mu \mathrm{M}$ in the wet season to $592 \mu \mathrm{M}$ in the dry season, and accounted for $90 \%$ of DIN, related to population density and chemical $\mathrm{N}$ fertilizer application. TDN was also dominated by $\mathrm{NO}_{3}^{-}(81 \%$, $80 \%$ ) both in the wet and dry seasons, DON contributed $11.5 \%$ and $18.5 \%$ of TDN, respectively.

\subsection{Nutrients distribution in the lagoons and coastal waters}

During the 2009 spring cruise the nutrient concentrations (with the exception of DON, DOP and PBSi) in XH Lagoon reflected linear dilution of freshwater by seawater (Fig. 2a). Nonlinear correlations with salinity were observed during April 2009 and August 2009. All nutrient concentrations were higher in summer than in spring except for the concentration $\mathrm{NO}_{3}^{-}$and that of $\mathrm{NO}_{2}^{-}$. DON represented $76 \pm 15 \%$ 
a
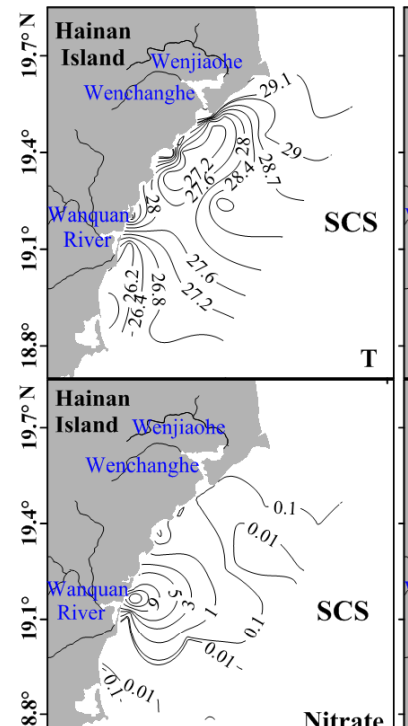

Nitrate

Z Hainan

- Island 1 ,

Wenchanghe

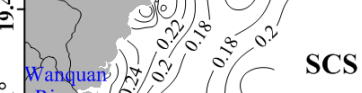

a.

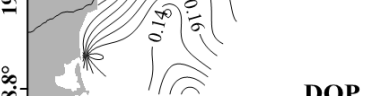

Hainan

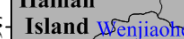

Wenchanghe

@.

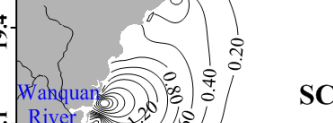

-

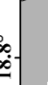

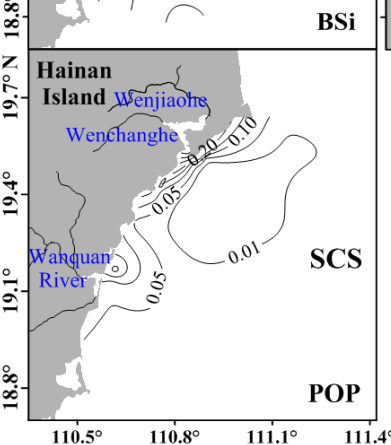

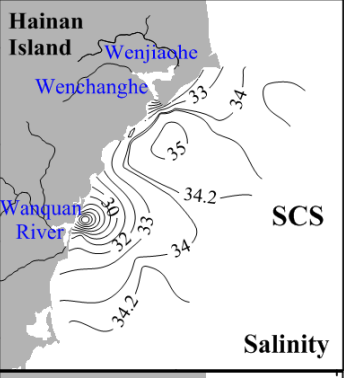

Hainan

Island Wenjiaothe

Wenchanghe

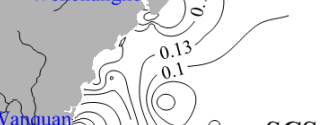

SCS

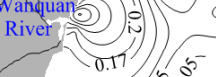

( 0.11

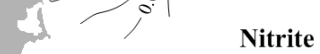

Hainan

Island w Wenjiaoth

Wenchanghe
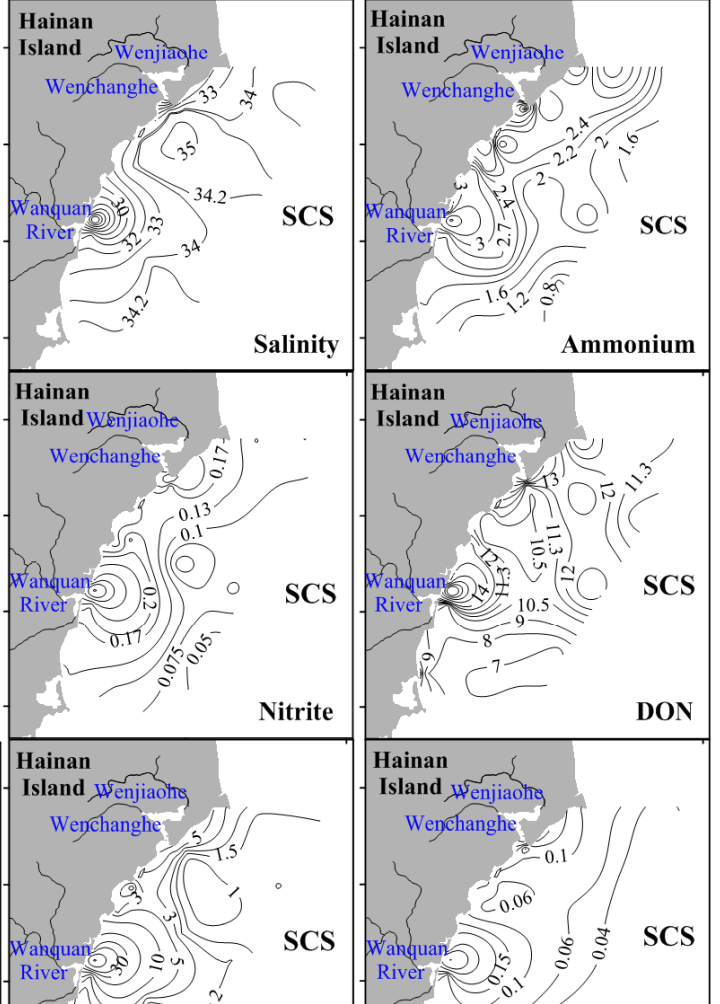

Island usenjiaots

Wenchange?

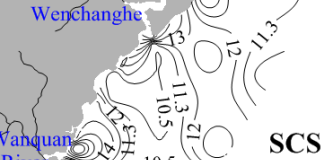

Rivet $2 \times)$ : ${ }^{\prime \prime}$
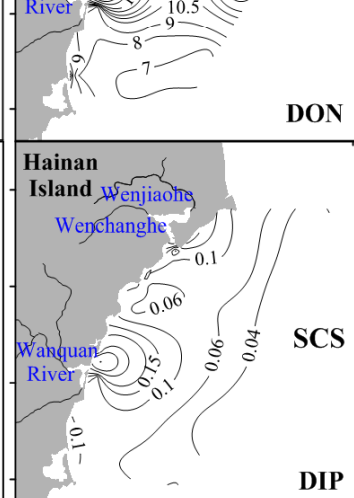

DSi

Hainan

Island Wyenjiaot

Wenchanghe

Island wenjiaoth

Wenchanghe

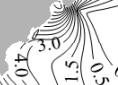

( 3.0$)$ m

3) 0

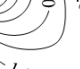

$\int_{0}$

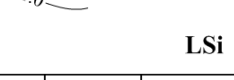

LSi

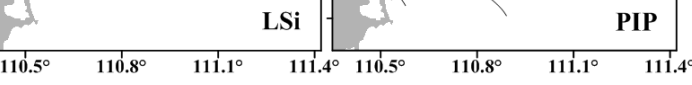

Fig. 3. Horizontal distributions of surface temperature $\left({ }^{\circ} \mathrm{C}\right)$, salinity, and nutrients $(\mu \mathrm{M})$ along the eastern coast of Hainan Island. (a) $18-$ 22 August 2007; (b) 27 July-2 August 2008; (c) 6-12 April 2009; (d) 29 August-1 September 2008; (e) 29 July-3 August 2009.

of TDN in summer, and was $36 \pm 15 \%$ in April 2009. DOP represented $50 \pm 20 \%$ and $47 \pm 20 \%$ of TDP in spring and summer, respectively. Low-salinity (1.8) water containing high nutrient concentrations $\left(\mathrm{NO}_{3}^{-}: 45.0 \mu \mathrm{M} ; \mathrm{DON}\right.$ :
$23.8 \mu \mathrm{M}$ ) was present in the west of the inner lagoon (station $\mathrm{XH5}$ ); this was related to input of terrigenous materials via river runoff. The average concentrations of $\mathrm{PO}_{4}^{3-}(0.7 \mu \mathrm{M})$ were a factor of 2.0-6.9 higher than in rivers entering $\mathrm{XH}$ 


\section{b}
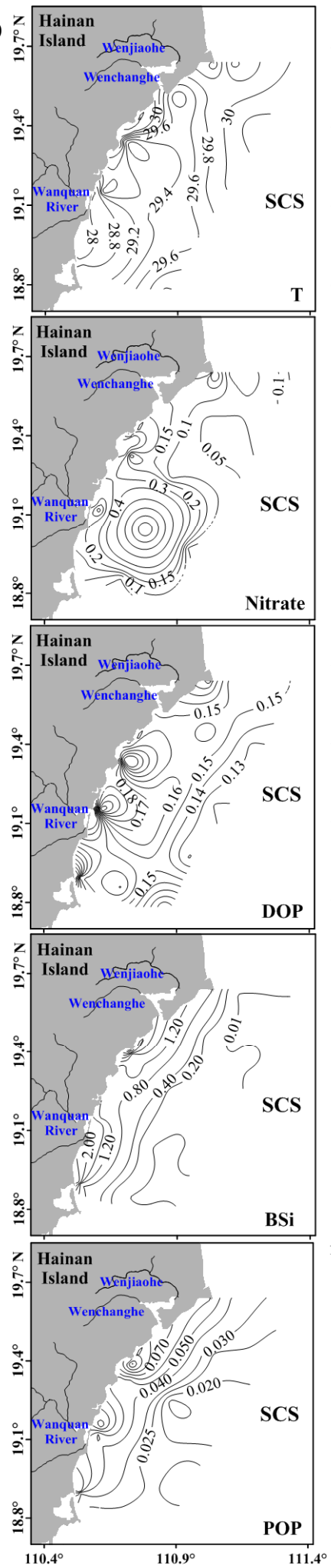
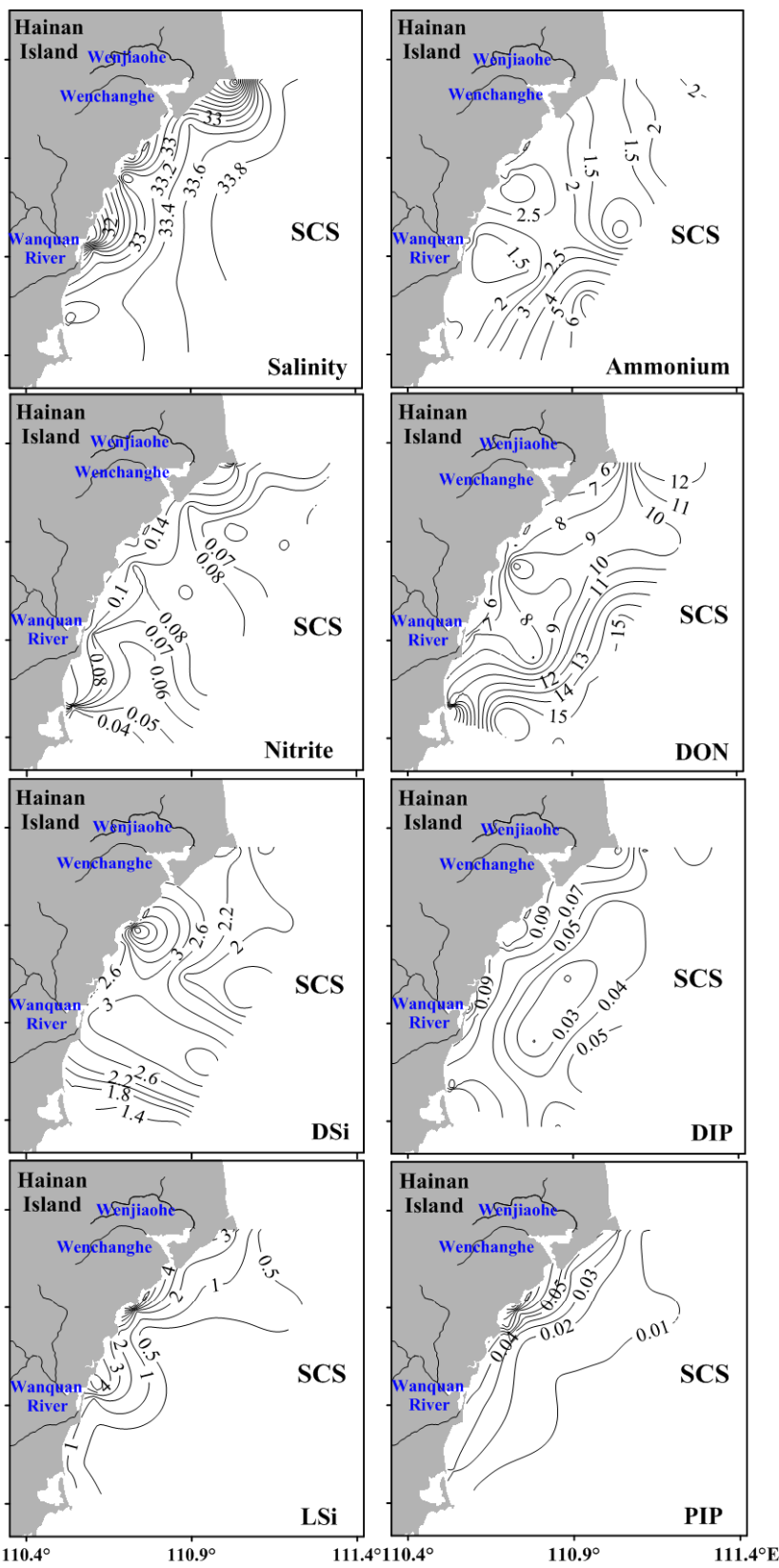

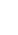




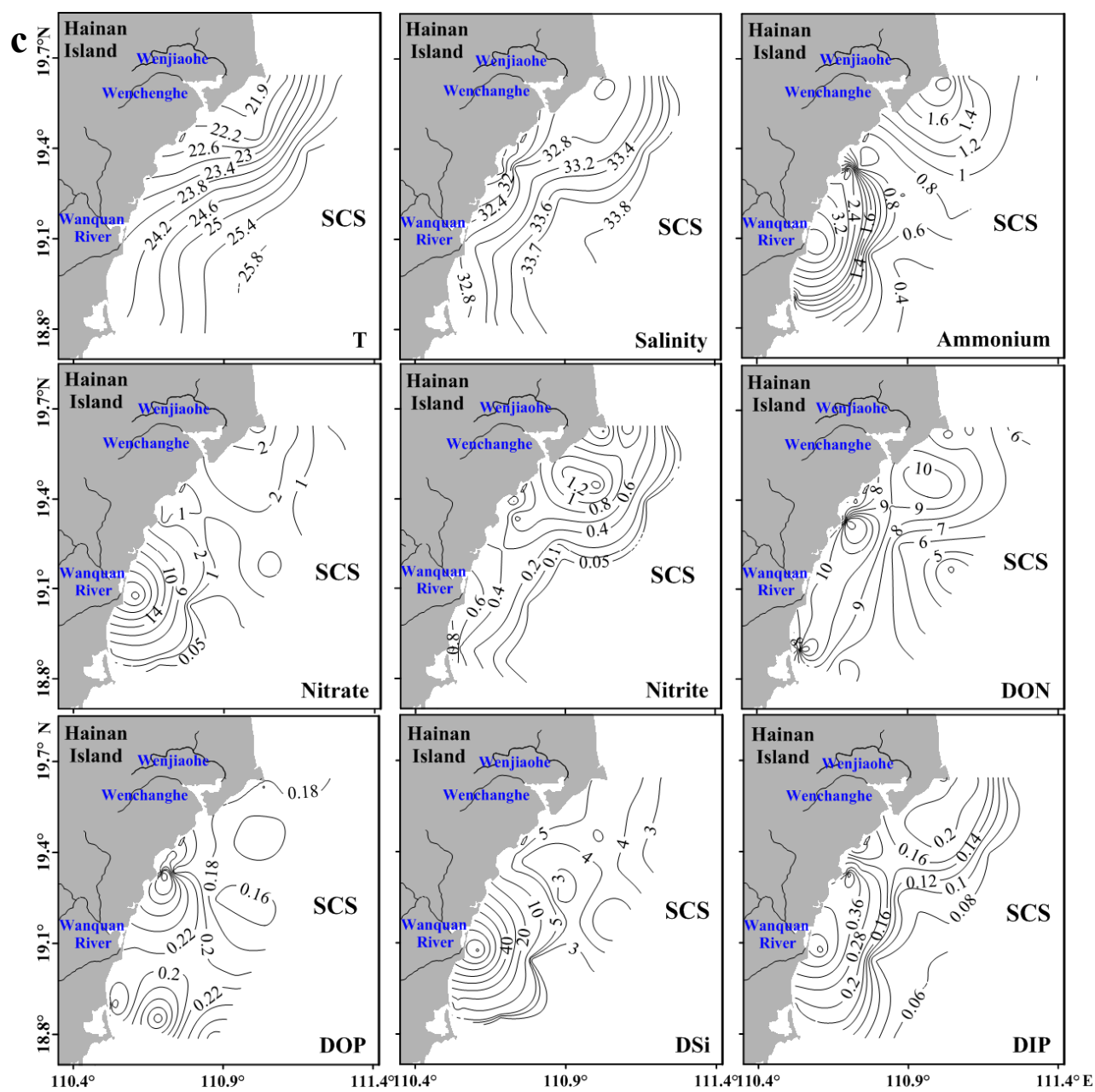

Fig. 3. Continued.

Lagoon, while DIN was higher in rivers. This resulted in DIN : $\mathrm{PO}_{4}^{3-}$ ratios of 3.0-173 (mean 48), which were significantly lower than in rivers (170-401; Table 2 ) around the lagoon.

In the inner part (salinity 9-16; shaded part, Fig. 2b) of LYH Lagoon, there was considerable variation in the nutrient concentration-salinity relationship because of aquaculture activities. In the tidal channel (salinity $>16$ ) all nutrients other than LSi showed rapid dilution (Fig. 2b). The increasing concentrations of $\mathrm{NH}_{4}^{+}$and $\mathrm{NO}_{2}^{-}$, and the stability of DON concentration at salinity $<16$ indicated input of regenerated $\mathrm{N}$ into the inner lagoon, where the maximum concentrations were observed. The average concentrations of nutrients, other than $\mathrm{NO}_{3}^{-}, \mathrm{PBSi}$ and $\mathrm{LSi}$, were higher in summer than in spring. DIN was generally dominated by $\mathrm{NH}_{4}^{+}$ (46-96\%) in both summer and spring. DON concentrations accounted for 31-98\% of TDN, and were significantly lower in April 2009. DOP represented 8-76\% of TDP. DSi concentrations in LYH Lagoon ranged from 6.02-86.4 $\mu \mathrm{M}$, and were significantly lower than in XH Lagoon. Large variability was found in the concentration of $\mathrm{PO}_{4}^{3-}(0.26-4.52 \mu \mathrm{M})$ in the lagoon, and the average concentration was $1.97 \mu \mathrm{M}$. This resulted in DIN : $\mathrm{PO}_{4}^{3-}$ ratios of 2.7-32 (mean 15), which were low relative to other systems in this study.

The concentrations of nutrients in coastal waters showed seasonal variations; they decreased significantly from inshore to offshore waters (except for DON); and they were higher in near-bottom layers than in surface water (except for DON and DOP) (Fig. 3). Nutrient horizontal distributions were generally consistent with surface salinity distribution, and isopleth paralleled with coastline except in August 2008 cruise. In addition, the nutrients distributions were quite similar to the freshwater plume extending from rivers into coastal area (Fig. 3a, c, e). A freshwater plume with high nutrient concentrations extended to the northeast in summer 2007 and 2009 (Fig. 3a, e), but extended southwest in spring 2009 (Fig. 3c). The nutrient concentrations decreased from south to north in August 2008, and terrigenous inputs were not evident (Fig. 3d). The concentrations increased from the west to the east in summer 2009 (Fig. 3e) and high nutrient 


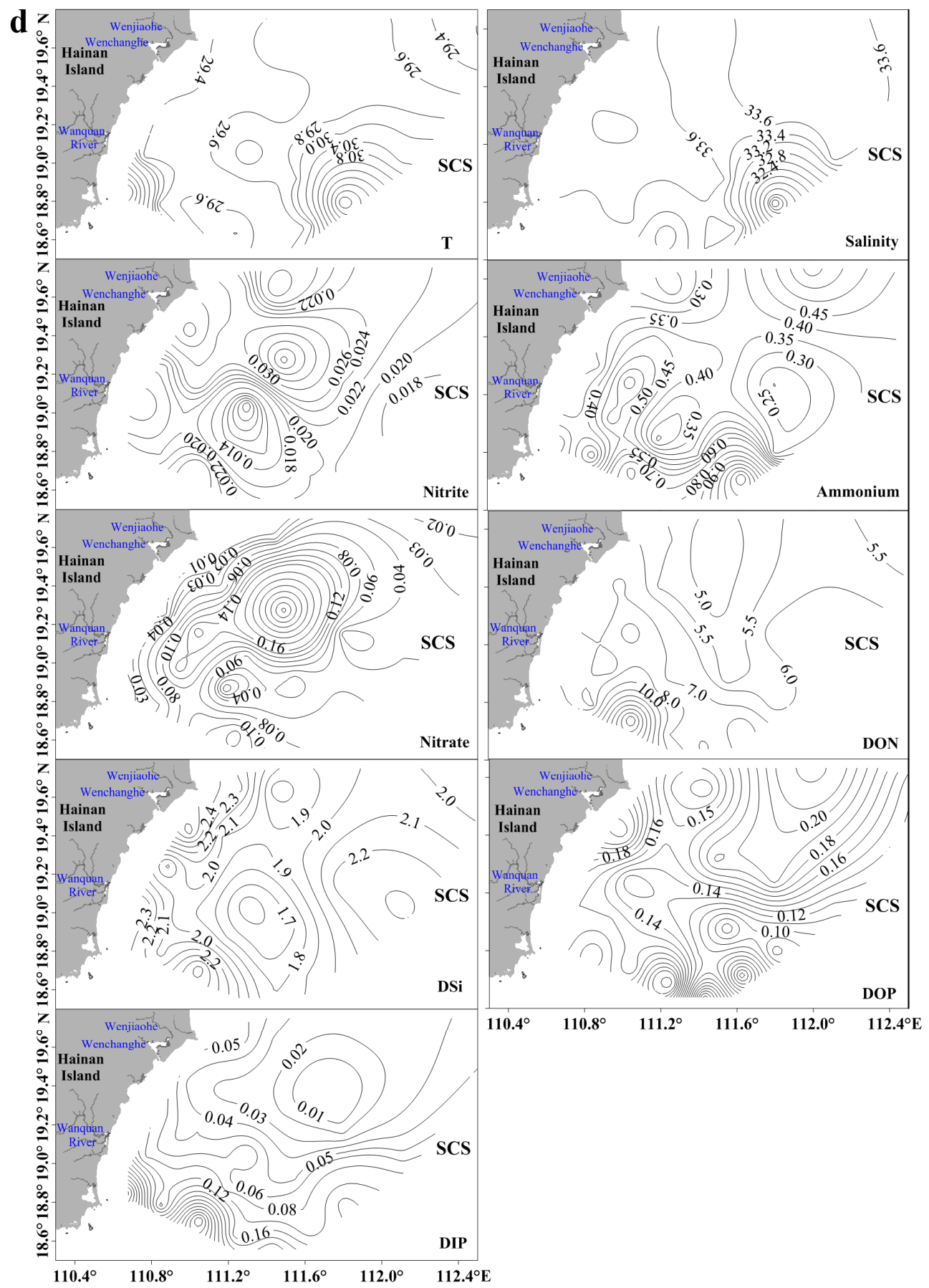

Fig. 3. Continued.

concentrations were present in Qiongzhou Strait, and nutrient isopleths in Qiongzhou Strait, which can be affected by Nandu River, were at $90^{\circ}$ to the coastline. DON represented 47-97, 47-98, 14-97 and 22-95\% of TDN in surface water in August 2007, July-August 2008, August 2008 and April 2009 , respectively. During the study period, DOP accounted for $27-91,32-95,3.7-92$ and $27-87 \%$ of TDP, respectively.
DON and DOP were the main components of TDN and TDP in offshore surface waters in our study region. DON and DOP concentrations were slightly higher in surface waters than in the near-bottom layer. In summer 2007 and 2008, the mean concentrations of PP in coastal water accounted for 52 and $37 \%$ of TP, and PIP accounted for 16 and $26 \%$ of TP, respectively. PP is an important factor in our study environments. 
e
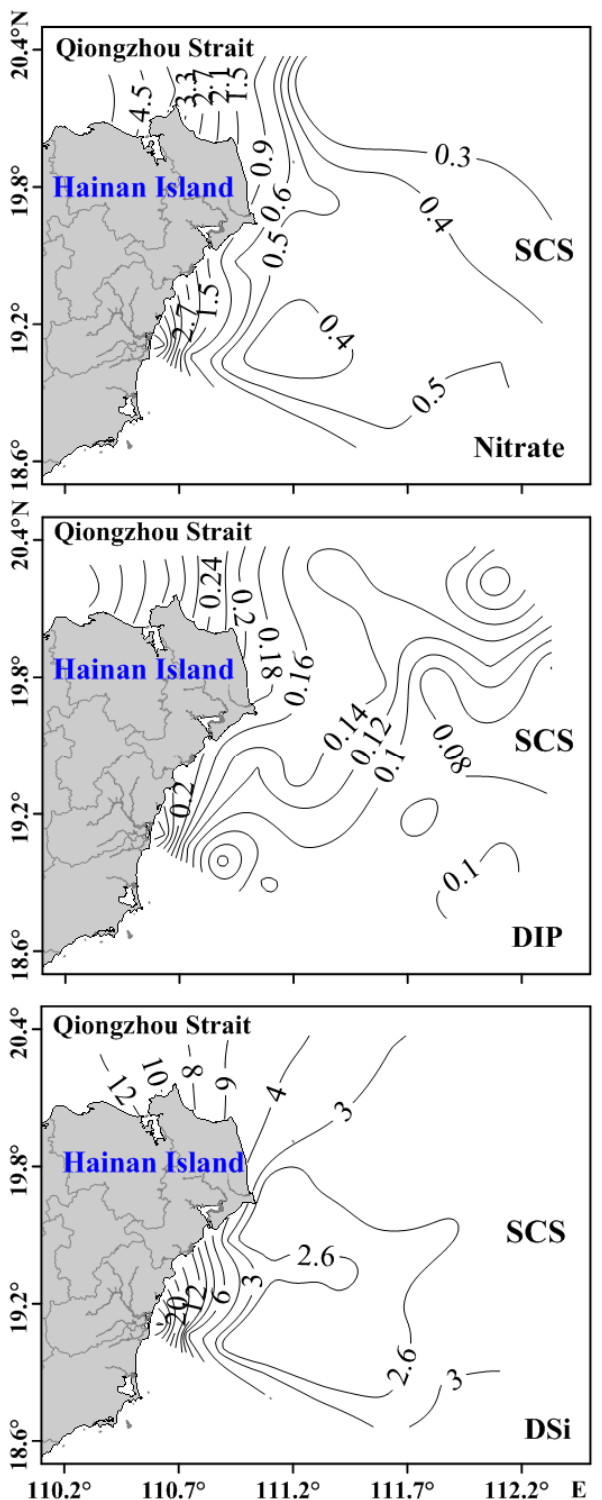
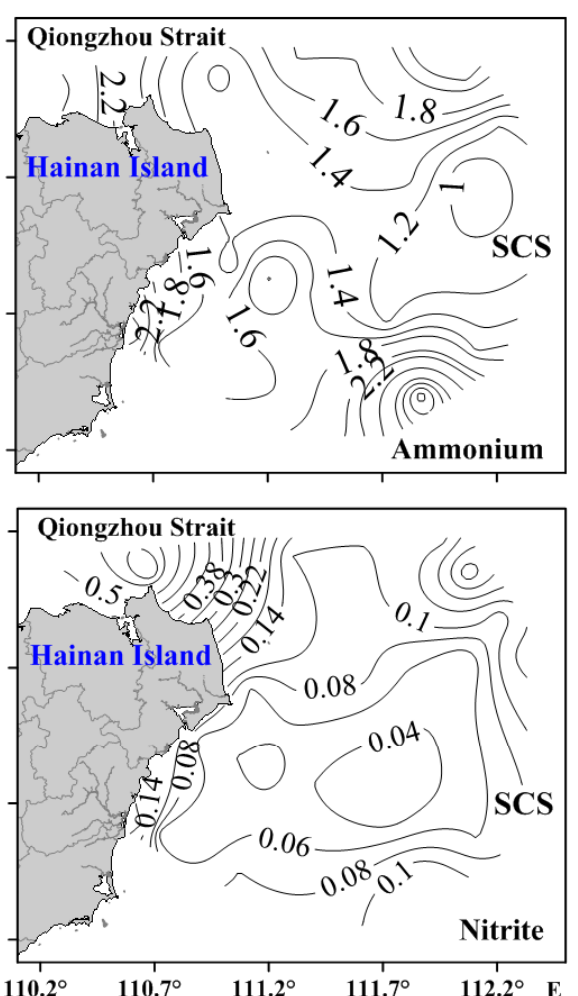

Fig. 3. Continued.

Molar ratios of DIN : $\mathrm{PO}_{4}^{3-}$ and DSi : DIN in August 2007, July-August 2008 and July-August 2009 were higher than the Redfield ratio. The DIN : $\mathrm{PO}_{4}^{3-}$ molar ratios ranged from 1.0 to 25 (average $11 \pm 11$ ) in August-September 2008, except for one site where the ratio was 51 . The DSi : DIN ratio was higher than or comparable to the Redfield ratio in both April 2009 and August 2008 (Table 2, S1) and decreased from nearshore to offshore waters. This indicates that $\mathrm{N}$ would be the limiting element for phytoplankton growth in shelf region, while $\mathrm{P}$ was the most limiting nutrient in nearshore region for phytoplankton growth because of excessive terrigenous $\mathrm{N}$ input. The PBSi : POC ratio was approximately 0.05 , based on POC measured in the neritic region in August 2007 (Tian, 2009). This value is within the 0.05-
1 range reported worldwide (Liu et al., 2007), although it is lower than the $\mathrm{Si}: \mathrm{C}$ ratio (0.13) for diatom growth under nutrient-sufficient conditions (Brzezinski, 1985).

\subsection{Nutrients variability at anchor stations}

Stations T2-2, T2-3 and 16 were located off Gaolong Bay. At station T2-3 in August 2007, the $\mathrm{NO}_{3}^{-}, \mathrm{NO}_{2}^{-}, \mathrm{PO}_{4}^{3-}$ and DSi concentrations were higher in near-bottom waters than in surface and sub-surface waters (Fig. 4a). The $\mathrm{NH}_{4}^{+}$, DON and DOP concentrations had a well-mixed vertical profile throughout the water column (Fig. 4a). High DON concentrations $(6.58-18.3 \mu \mathrm{M})$ were observed and comprised $72-90 \%$ of TDN. The DOP concentrations were $0.04-0.20 \mu \mathrm{M}$. The DIN : $\mathrm{PO}_{4}^{3-}$ ratio in August 2007 decreased from 12-61 in 

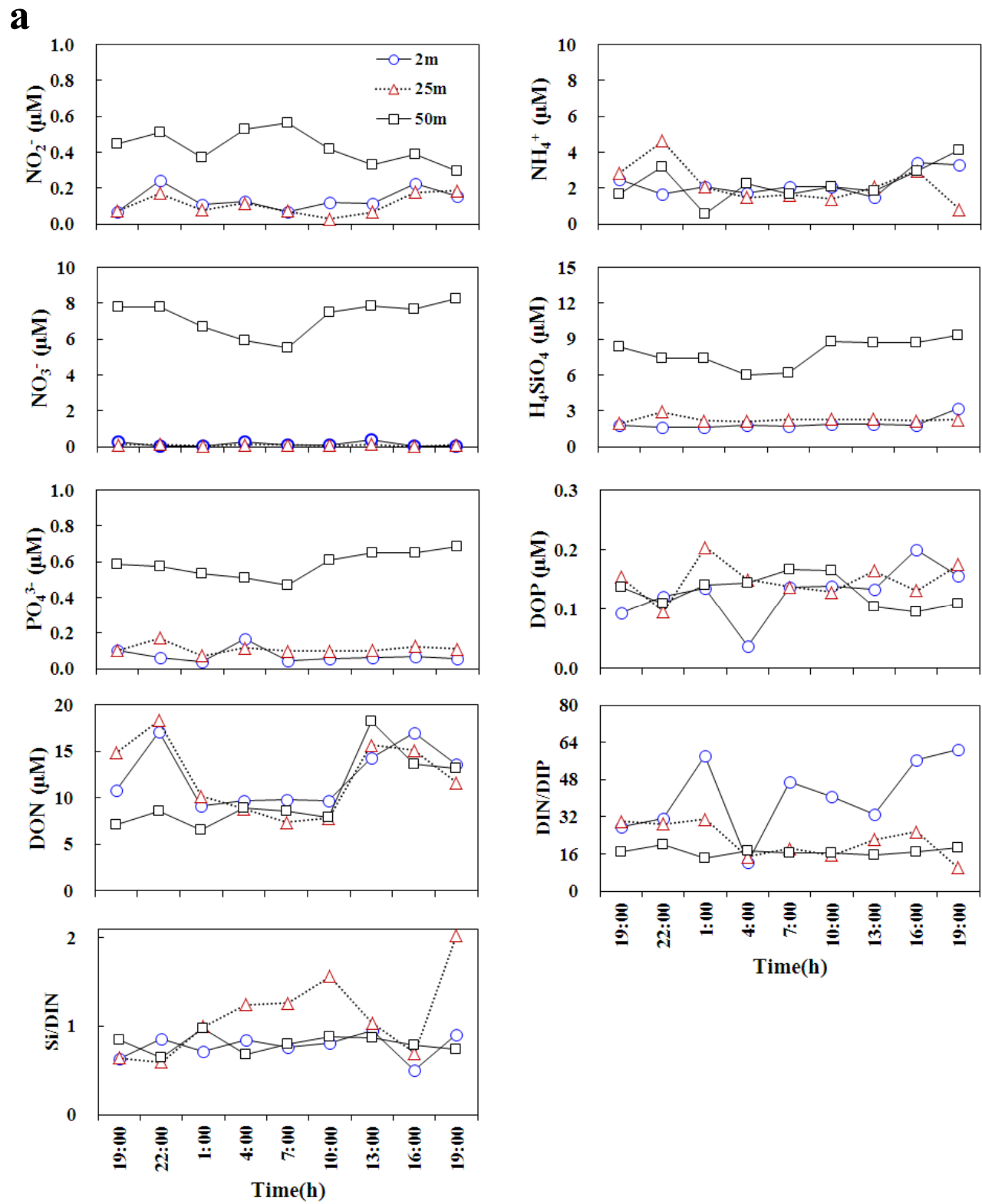

Time(h)

Fig. 4. Concentrations of nutrients $(\mu \mathrm{M})$ at (a) anchor station T2-3 in August 2007, (b) station T2-2 in July 2008 and (c) station 15 in July 2009. The tide heights $(\mathrm{cm})$ during July 2008 and July 2009 are provided, and the red circle represents the sampling time. No data regarding tidal variations were available for August 2007, and consequently the tide height is not show.

surface water to $14-20$ in near-bottom water. The DSi : DIN ratio ranged from 0.50 to 0.95 in surface water and $0.64-0.98$ in near-bottom water.

Sampling at station T2-2 commenced in 29-30 July 2008. The concentrations of all nutrients suggested a well-mixed water column (Fig. 4b). The nutrient concentrations varied by a factor of $1-3$ for $\mathrm{Si}(\mathrm{OH})_{4}, \mathrm{TDN}, \mathrm{DON}, \mathrm{TDP}$ and DOP, and by 3-11 times for $\mathrm{NO}_{2}^{-}, \mathrm{NO}_{3}^{-}, \mathrm{PO}_{4}^{3-}$ and $\mathrm{NH}_{4}^{+}$. The DIN : $\mathrm{PO}_{4}^{3-}$ ratio decreased from 19-138 in surface water to 17-48 in near-bottom water. The DSi : DIN ratio increased from $0.5-1.3$ in surface water to $0.8-3.0$ in near- bottom water. High concentrations of DON were observed $(5.1-9.6 \mu \mathrm{M})$, and comprised up to $60 \%$ of TDN throughout the water column. The DOP concentrations were 0.09$0.24 \mu \mathrm{M}$, represented $41-91 \%$ of TDP, and showed a wellmixed profile (Fig. 4b).

At station 16 in August 2009 the nutrient concentrations showed strong vertical mixing at depths $<30 \mathrm{~m}$ (Fig. 4c), and the vertical distribution of nutrients was similar to that at station T2-3. The $\mathrm{NH}_{4}^{+}$concentrations $(0.24-7.47 \mu \mathrm{M})$ were variable throughout the water column. The $\mathrm{NO}_{3}^{-}$concentrations were $0.07-0.57 \mu \mathrm{M}$ for depths $<30 \mathrm{~m}$, and reached 

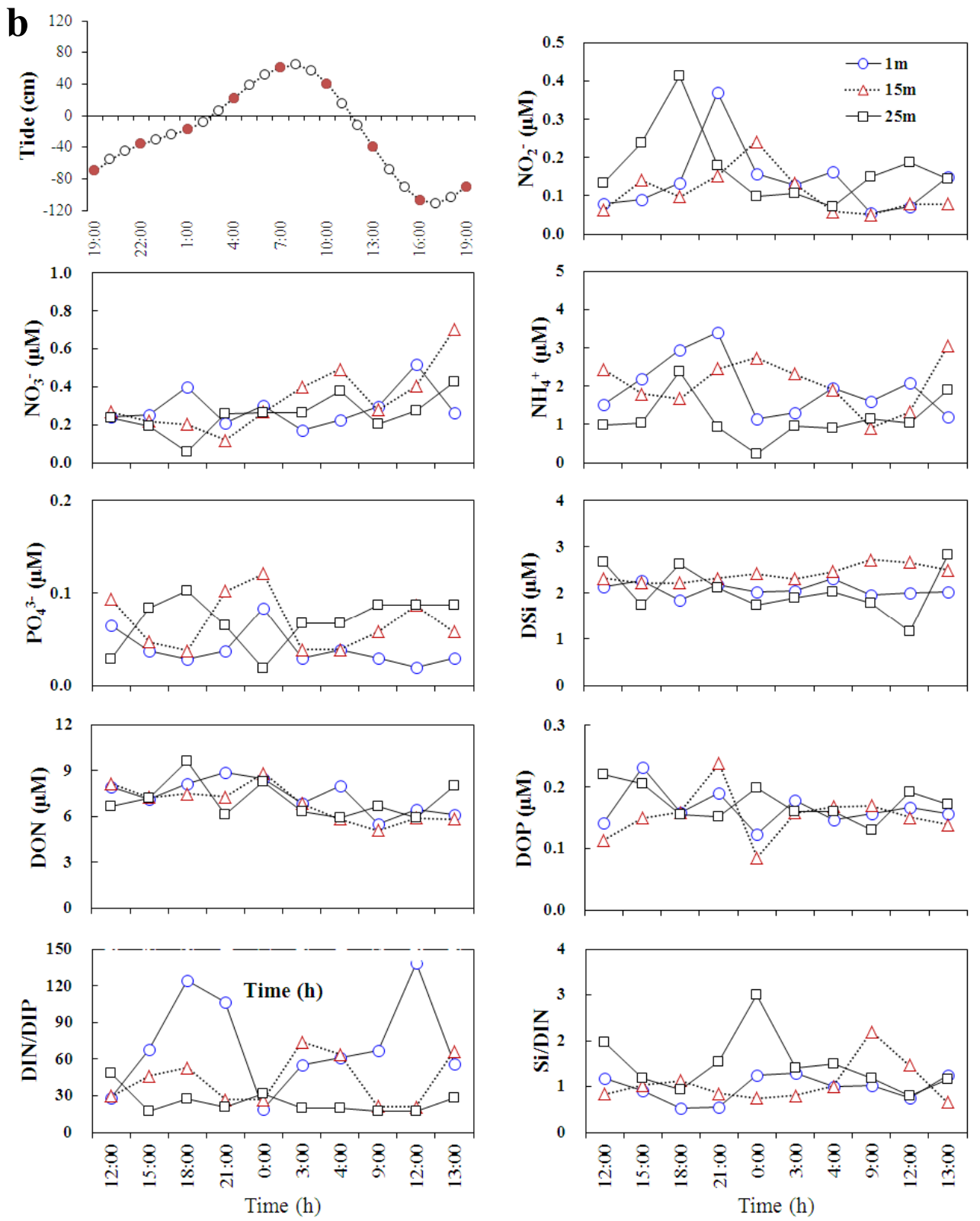

Fig. 4. Continued.

3.88-9.02 $\mu \mathrm{M}$ in bottom waters. The concentrations of DSi increased steadily from $2.82-4.26 \mu \mathrm{M}$ at depths $<30 \mathrm{~m}$ to $7.64-13.0 \mu \mathrm{M}$ in bottom waters. For depths $<30 \mathrm{~m}$ the $\mathrm{DIN}: \mathrm{PO}_{4}^{3-}$ ratio was 3.6-21 (average 11), and in bottom water was $10-17$ (average 14). The DSi : DIN ratio decreased from 0.4-12 (average: 2.1 ) at depths $<30 \mathrm{~m}$ to $1.0-1.4$ (average: 1.1) in bottom waters.

\subsection{Water and nutrient budgets in the lagoons}

Liu et al. (2011) and Li et al. (2013) have provided detailed descriptions of the dissolved nutrient budgets in the WWE and WQE, respectively. Here we describe nutrient budgets for $\mathrm{XH}$ and LYH lagoons in Table 4, and particulate nutrient budgets for the WWE and WQE.

For the water budget, wastewater from domestic, industrial and aquaculture effluents discharge directly into the lagoons has been ignored as no data were available. The mean submarine groundwater discharge into LYH Lagoon was calculated to be $4.11 \times 10^{6} \mathrm{~m}^{3} \mathrm{day}^{-1}$, based on the excess radium isotopes and the water age in the lagoon in April 2010 (Ji et al., 2013). The total freshwater discharge from rivers into $\mathrm{XH}$ and $\mathrm{LYH}$ lagoons was $26.5 \mathrm{~m}^{3} \mathrm{~s}^{-1}$ and $0.4 \mathrm{~m}^{3} \mathrm{~s}^{-1}$, respectively. Precipitation levels of $65.3 \times 10^{6} \mathrm{~m}^{3} \mathrm{yr}^{-1}$ and $14.2 \times 10^{6} \mathrm{~m}^{3} \mathrm{yr}^{-1}\left(V_{\mathrm{P}}\right)$ were 

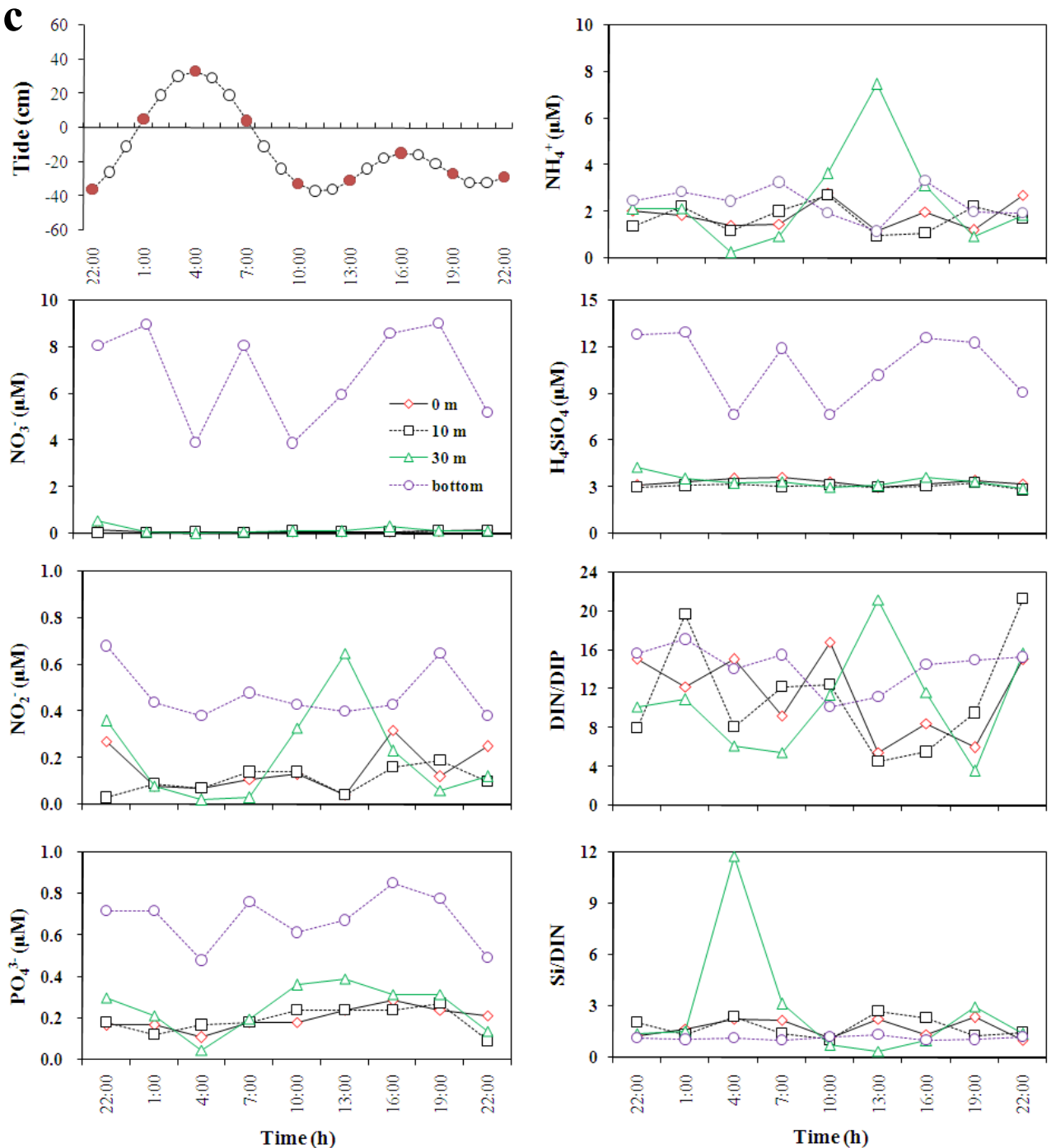

Fig. 4. Continued.

reduced by $35.4 \times 10^{6} \mathrm{~m}^{3} \mathrm{yr}^{-1}$ and $7.80 \times 10^{6} \mathrm{~m}^{3} \mathrm{yr}^{-1}$ of evaporation $\left(V_{\mathrm{E}}\right)$ in $\mathrm{XH}$ and $\mathrm{LYH}$ lagoons, respectively. Based on water balance, the net water exchanges $\left(V_{\mathrm{R}}\right)$ from $\mathrm{XH}$ and $\mathrm{LYH}$ lagoons to the SCS were calculated to be $864 \times 10^{6} \mathrm{~m}^{3} \mathrm{yr}^{-1}$ and $1519 \times 10^{6} \mathrm{~m}^{3} \mathrm{yr}^{-1}$, respectively. The water exchange flow $\left(V_{\mathrm{X}}\right)$ from the SCS to XH and $\mathrm{LYH}$ lagoons was $717 \times 10^{6} \mathrm{~m}^{3} \mathrm{yr}^{-1}$ and $2660 \times 10^{6} \mathrm{~m}^{3} \mathrm{yr}^{-1}$, respectively. The volumes $\left(V_{\mathrm{S}}\right)$ of $\mathrm{XH}$ and $\mathrm{LYH}$ lagoons were $6.6 \times 10^{7} \mathrm{~m}^{3}$ and $5.0 \times 10^{7} \mathrm{~m}^{3}$, respectively. The total water exchange times $(\tau)$ for $\mathrm{XH}$ and $\mathrm{LYH}$ lagoons, estimated from the $V_{\mathrm{S}} /\left(V_{\mathrm{X}}+V_{\mathrm{R}}\right)$ ratio, were 15.2 days and 4.4 days, respectively.

Nutrient transport fluxes from river, rainwater and submarine groundwater into the study systems were determined from surveys undertaken in the period 2006-2009. The nutrient concentrations in rainwater were based on measurements made during 2006-2009 at Wenchang, Qinglan (Liu et al., 2011). Submarine groundwater discharge (SGD) was ignored as no data were available for $\mathrm{XH}$ Lagoon. Atmospheric deposition as a source of nutrient input was very limited because of the small surface area involved. Nutrient budget results showed that nutrient loads in XH Lagoon are mainly derived from riverine inputs, and the lagoon behaves as a sink for all nutrients except $\mathrm{PO}_{4}^{3-}$ and DON. As one nutrient source, river discharge into LYH Lagoon is very limited $\left(0.4 \mathrm{~m} \mathrm{~s}^{-1}\right.$; Ji et al., 2013) and contains low concentrations of dissolved inorganic nutrients (mean values include $\mathrm{NO}_{2}^{-}: 0.67 \mu \mathrm{M}, \mathrm{NO}_{3}^{-}: 1.63 \mu \mathrm{M}, \mathrm{NH}_{4}^{+}: 3.40 \mu \mathrm{M}, \mathrm{PO}_{4}^{3-}$ : $1.30 \mu \mathrm{M}$, DSi: $25.2 \mu \mathrm{M}$ ). Additionally, the amounts of dissolved organic and particulate nutrients were based on measurements for rivers around XH Lagoon. The results showed that LYH Lagoon behaved as a source of $\mathrm{NO}_{2}^{-}, \mathrm{NH}_{4}^{+}$, PIP, POP, PBSi, and LSi, and as a sink for $\mathrm{NO}_{3}^{-}, \mathrm{PO}_{4}^{3-}$, DSi, TDN, DON, TDP and DOP. Groundwater was the major 
Table 3. (A) Observed nutrient yields (Obs.) $\left(\times 10^{3} \mathrm{~mol}\right.$ $\mathrm{km}^{-2} \mathrm{yr}^{-1}$ ) in rivers of the eastern Hainan Island. (B) Areal nutrients yields $\left(\times 10^{3} \mathrm{~mol} \mathrm{~km}^{-2} \mathrm{yr}^{-1}\right)$ for tropical and nontropical rivers Data sources: ${ }^{\mathrm{a}}$, Jennerjahn (2012); ${ }^{\mathrm{b}}$, Liu et al. (2009).

Panel A: observed nutrient yields $\left(\times 10^{3} \mathrm{~mol} \mathrm{~km}^{-2} \mathrm{yr}^{-1}\right)$ of rivers along the eastern Hainan Island

\begin{tabular}{llll}
\hline & DIN & $\mathrm{PO}_{4}^{3-}$ & DSi \\
\hline WC & 51 & 0.5 & 120 \\
WJ & 37 & 0.4 & 76 \\
WQ & 62 & 0.9 & 448 \\
JQJ & 78 & 1.1 & 134 \\
LG & 43 & 0.2 & 160 \\
LT & 77 & 0.5 & 268 \\
LW & 43 & 0.3 & 319 \\
TY & 46 & 0.1 & 234 \\
\hline
\end{tabular}

Panel B: the areal yields $\left(\times 10^{3} \mathrm{~mol} \mathrm{~km}^{-2} \mathrm{yr}^{-1}\right)$

of nutrients in the tropical and nontropical rivers

\begin{tabular}{llll}
\hline & DIN & DSi & $\mathrm{PO}_{4}^{3-}$ \\
\hline Large tropical rivers $^{\mathrm{a}}$ & 13 & 81 & 0.9 \\
Large nontropical rivers $^{\mathrm{a}}$ & 23 & 36 & 1.6 \\
Daguhe, China $^{\mathrm{b}}$ & 16 & 5.4 & 0.03 \\
Keum, Korea $^{\mathrm{b}}$ & 110 & 50 & 0.8 \\
Yongjiang, China $^{\mathrm{b}}$ & 104 & 147 & 2.6 \\
Pearl River, China $^{\mathrm{b}}$ & 67 & 91 & 0.6 \\
Kallada, India $^{\mathrm{a}}$ & 10 & 81 & 6.0 \\
Brantas, Indonesia $^{\mathrm{a}}$ & 91 & 149 & 2.9 \\
Citanduy, Indonesia $^{\mathrm{a}}$ & 51 & 284 & 2.0 \\
\hline
\end{tabular}

source of nutrients entering LYH Lagoon. In addition, the nutrient budgets indicated that the WWE behaved as a sink of LSi, and as a source of PIP, POP and PBSi. Both Shamei Lagoon and the WQ tidal inlet behaved as a source of particulate $\mathrm{P}$ and silicon, without considering wastewater and aquaculture effluents.

\section{Discussion}

\subsection{Nutrient dynamics in rivers}

The observed spatiotemporal variations of dissolved nutrients in rivers were probably the result of the systems and seasonally varying interaction of natural and anthropogenic factors. Compared with other small to medium-sized rivers of temperate China (Liu et al., 2009), the DIN concentrations $(16.0-144 \mu \mathrm{M})$ in our study rivers were lower, and were comparable to subtropical rivers of China (Liu et al., 2009). The DIN levels were lower than in some tropical rivers that are significantly affected by human activities, such as Naliu River (55-220 $\mu \mathrm{M}$; Kaiser et al., 2013) and Tamsui River (Wen et al., 2008) in China, Wonokromo River $(123 \mu \mathrm{M})$ (Jennerjahn et al., 2004) and Brantas River (142-169 $\mu \mathrm{M})$ in
Indonesia (Jennerjahn, 2012). However, DIN concentrations were much higher than in other large and less disturbed rivers worldwide, such as the Amazon and Zaire (Cai et al., 2004). Anthropogenic activities (e.g., agriculture, aquaculture and deforestation) may be major sources of DIN in our study rivers. In these rivers, the mean concentrations of $\mathrm{PO}_{4}^{3-}$ were within the range of pristine $(0.5 \mu \mathrm{M})$ to clean water $(1.4 \mu \mathrm{M})$, and higher than in other Chinese rivers, including the Yanglujiang, Daguhe and Oujiang (Liu et al., 2009). Population has been growing in recent decades in the cities of Wenchang, Qionghai, and Wanning (Fig. 5; Hainan Statistical Yearbook, 2010). Cultivated areas for crop production decreased in those cities in the past decades, while crop yield per unit area increased from $1095 \mathrm{~kg} \mathrm{ha}^{-1}$ in 1952, $4083 \mathrm{~kg} \mathrm{ha}^{-1}$ in 1999. Hence, more fertilizer was used to increase crop production from 1987-2011, especially in Qionghai, and more than 50\% of the applied $\mathrm{N}$ may have been transported to rivers because of the low fertilizer uptake efficiency (approximately $30-50 \%$ in tropical regions; Han et al., 2010). Wastewater can increase nutrient levels, as shown for Tamsui River in Taiwan (Wen et al., 2008). Thus, the influence of human activities is very important in this tropical region, and must be considered.

Because of their geological and climatic settings, tropical river basins play a major role in chemical weathering and transfer of DSi to rivers and oceans (Bouwman et al., 2013). The concentrations of DSi (range 96.2-396 $\mu \mathrm{M}$, mean $252 \mu \mathrm{M}$ ) in study rivers were high for tropical river systems (global average level in tropical systems approximately 180$190 \mu \mathrm{M}$; Jennerjahn, 2012), and also higher than the mean concentration for Asian freshwater systems $(196 \mu \mathrm{M}$; Cornelis et al., 2011). DSi is mainly derived from natural sources (e.g., chemical weathering), and is little affected by human activities (Jennerjahn et al., 2009). The combination of lithology, climate and tectonic activity are frequently cited to explain high DSi values (Liu et al., 2009). Additionally, deforestation is also well-known for enhancing erosion and transporting nutrients to rivers. Silicate and carbonate rocks are the main rock types of Hainan Island, and chemical weathering rate $\left(42 \mathrm{t} \mathrm{km}^{-2} \mathrm{yr}^{-1} ; \mathrm{Li}, 2009\right)$ in the eastern Hainan Island is higher than the average global level $\left(36 \mathrm{t} \mathrm{km}^{-2} \mathrm{yr}^{-1}\right)$. Rivers in the study area are all dominated by precipitation, and forest and mangroves have been deforested for agriculture and aquaculture. These factors may explain the high DSi levels found in the freshwater systems in this study.

It is known that riverine transport of phosphorus mainly exists in the solid phase; DIP load is increased by as much as five times because of release of phosphate from particles entering the sea. Average SPM concentrations in the WC, WJ and WQ rivers $\left(19.2 \mathrm{mg} \mathrm{L}^{-1}\right)$ were low compared to other Chinese rivers (7-44 $\mathrm{mg} \mathrm{L}^{-1}$; Liu et al., 2009), and PP levels were lower than the Daguhe $(2.86 \mu \mathrm{M})$, Jiulongjiang $(2.47 \mu \mathrm{M})$ and Changjiang $(2.87 \mu \mathrm{M})$ (Liu et al., 2009). As a good proxy for diatom abundance, the average concentrations of PBSi in the Amazon, Connecticut, Danube, 
Table 4. Nutrient budgets $\left(10^{6} \mathrm{~mol} \mathrm{yr}^{-1}\right)$ in Xiaohai (XH) and Laoyehai (LYH) lagoons. $C_{1}$ and $C_{2}$ are the average nutrient concentrations in the system of interest and the adjacent system, respectively. $V_{\mathrm{R}} C_{\mathrm{R}}, V_{\mathrm{X}} C_{\mathrm{X}}$ and $\Delta$ are the residual nutrient transport out of the system of interest, the mixing exchange flux of nutrients, and the non-conservative flux of nutrients, respectively. Negative and positive signs of $\Delta$ indicate that the system is a sink or a source, respectively.

\begin{tabular}{|c|c|c|c|c|c|c|c|c|c|c|c|c|c|}
\hline & $\mathrm{NO}_{3}^{-}$ & $\mathrm{NO}_{2}^{-}$ & $\mathrm{NH}_{4}^{+}$ & $\mathrm{PO}_{4}^{3-}$ & $\mathrm{Si}(\mathrm{OH})_{4}$ & TDN & DON & TDP & DOP & PIP & POP & PBSi & LSi \\
\hline \multicolumn{14}{|c|}{ Freshwater discharge $\left(=V_{\mathrm{Q}} C_{\mathrm{Q}}\right)$} \\
\hline $\mathrm{XH}$ & 40.0 & 0.52 & 7.28 & 0.26 & 184 & 60.3 & 13.0 & 2.52 & 2.26 & 2.15 & 1.56 & 18.6 & 163 \\
\hline LYH & 0.03 & 0.007 & 0.04 & 0.02 & 0.32 & 0.91 & 0.20 & 0.04 & 0.03 & 0.03 & 0.02 & 0.28 & 2.47 \\
\hline \multicolumn{14}{|c|}{ Atmospheric deposition $\left(=V_{\mathrm{P}} C_{\mathrm{P}}\right)$} \\
\hline $\mathrm{XH}$ & 1.10 & 0.01 & 1.40 & 0.02 & 0.07 & 3.37 & 0.85 & 0.04 & 0.02 & n.a. & n.a. & n.a. & n.a. \\
\hline LYH & 0.24 & 0.003 & 0.31 & 0.004 & 0.01 & 0.74 & 0.17 & 0.009 & 0.005 & n.a. & n.a. & n.a. & n.a. \\
\hline \multicolumn{14}{|c|}{ Groundwater discharge $\left(=V_{\mathrm{G}} C_{\mathrm{G}}\right)$} \\
\hline LYH & 318 & 1.11 & 8.04 & 18.2 & 256 & 510 & 176 & 30.5 & 12.3 & n.a. & n.a. & n.a. & n.a. \\
\hline \multicolumn{14}{|c|}{ Residual flow $\left(=V_{\mathrm{R}} C_{\mathrm{R}}, C_{\mathrm{R}}=\left(C_{1}+C_{2}\right) / 2\right)$} \\
\hline XH & -4.85 & -0.42 & -3.35 & -0.32 & -62.5 & -22.3 & -13.7 & -0.62 & -0.29 & -0.48 & -0.61 & -6.01 & -45.4 \\
\hline LYH & -5.22 & -1.57 & -19.8 & -1.56 & -37.8 & -63.6 & -37.1 & -2.19 & -0.64 & -0.60 & -0.69 & -5.52 & -26.0 \\
\hline \multicolumn{14}{|c|}{ Mixing exchange $\left(=V_{\mathrm{X}} C_{\mathrm{X}}, C_{\mathrm{X}}=\left(C_{2}-C_{1}\right)\right)$} \\
\hline $\mathrm{XH}$ & -5.24 & 0.012 & -3.30 & -0.35 & -91.6 & -18.8 & -10.2 & -0.52 & -0.16 & -0.75 & -0.87 & -6.58 & -74.0 \\
\hline LYH & -7.85 & -2.85 & -60.8 & -4.79 & -87.2 & -155 & -83.8 & -5.78 & -1.01 & -1.94 & -1.91 & -6.70 & -85.6 \\
\hline \multicolumn{14}{|c|}{ Sink/source $(\Delta Y=\Sigma$ outflux $-\Sigma$ influx $)$} \\
\hline $\mathrm{XH}$ & -28.0 & -0.12 & -2.04 & 0.40 & -30.0 & -22.6 & 10.1 & -1.42 & -1.83 & -0.92 & -0.078 & -5.96 & -43.8 \\
\hline LYH & -306 & 3.30 & 72.1 & -11.8 & -131 & -293 & -55.5 & -22.5 & -10.7 & 2.51 & 2.57 & 11.9 & 109 \\
\hline
\end{tabular}

Rhine, Mississippi, Lena and Congo rivers $(28 \mu \mathrm{M}$, range from $2.68 \pm 0.52 \mu \mathrm{M}$ to $73.9 \pm 17.6 \mu \mathrm{M}$; Conley, 1997) was higher than the average PBSi levels $(6.71 \mu \mathrm{M})$ in rivers along the eastern coast of Hainan Island. The PBSi levels in these rivers were also lower than those in other Chinese rivers in the vicinity of Jiaozhou Bay (2.16-50.5 $\mu \mathrm{M}$; Liu et al., 2008). The contribution of PBSi to total silicon (silicic acid plus $\mathrm{PBSi}$ ) in rivers in this study was lower than in other rivers worldwide (16\%; Conley, 1997).

We estimated the areal yields of nutrients as the product of nutrient concentration with average freshwater discharge divided by the drainage area (Table 3). Both DIN and $\mathrm{PO}_{4}^{3-}$ areal yields in study rivers were higher than the average yields of large tropical and nontropical rivers which estimated based on the formulas of Smith et al. (2003). In addition, the areal yields of DIN in rivers were higher than in the tropical Kallada River (Table 3). The areal yields of $\mathrm{PO}_{4}^{3-}$ in rivers were significantly lower than those in the Kallada and Citanduy rivers (Table 3 ). While both DIN and $\mathrm{PO}_{4}^{3-}$ areal yields were lower than those in the tropical Brantas River (Table 3), which is located in the most favorable region on the Earth with regard to weathering and erosion conditions (Jennerjahn, 2012), and were also lower than in small temperate rivers, such as the Keum and Yongjiang rivers which are significantly affected by anthropogenic (Liu et al., 2009; Table 3). On a global scale the DIN and DIP yields showed significantly relationships with population density and runoff per unit area (Smith et al., 2003). Population density was 244 inhabitants per $\mathrm{km}^{-2}$ in 2010 (Hainan Statistical Yearbook, 2011) and runoff per area was low compared with other rivers. High anthropogenic $\mathrm{N}$ and $\mathrm{P}$ inputs can lead to high areal yields of DIN and DIP. Anthropogenic activities may be the main reason for high $\mathrm{N}$ areal yields in the study area. The use of fertilizer in Wenchang $\left(2600 \mathrm{~kg} \mathrm{ha}^{-1}\right)$, Qionghai $\left(5700 \mathrm{~kg} \mathrm{ha}^{-1}\right)$, and Wanning $\left(2100 \mathrm{~kg} \mathrm{ha}^{-1}\right)$ in 2009 (Hainan Statistical Yearbook, 2010) were much higher than the global average $\left(90 \mathrm{~kg} \mathrm{ha}^{-1}\right.$; Jennerjahn, 2012). The uptake efficiency of nitrogen fertilizer was only 30-50\% in the tropical region of China (Han et al., 2010). Under such conditions nitrogen could easily be washed into the rivers, resulting in high nitrogen yields. While $\mathrm{P}$ yields were low the tropical rivers systems in our study, which might be related to adsorptions onto particulates as in the other Chinese rivers (Liu et al., 2009). P emission was 3-4\% from soils in Jakenan in Indonesia (Jennerjahn et al., 2009). P emission in our study area might be significantly lower than $\mathrm{N}$ and that might be one reason for the low $\mathrm{P}$ yield in those rivers.

The areal yields of DSi from the study rivers (particularly the WQ) were significantly higher than the average yields reported for large tropical and nontropical rivers. The average areal yield of DSi from the WQ $\left(448 \times 10^{3} \mathrm{~mol} \mathrm{~km}^{-2} \mathrm{yr}^{-1}\right)$ was much higher than from the tropical Citanduy River in Indonesia, which has a drainage area comparable to that of the WQ. DSi areal yields were also significantly higher than for other Chinese rivers (Table 3). High chemical weathering rates may be responsible for high DSi areal yields.

\subsection{Nutrient dynamics in lagoons and coastal waters}

The nutrient-rich Longtouhe (LT) and Longweihe (LW) rivers (Table 2) empty directly into the northern lagoon, 

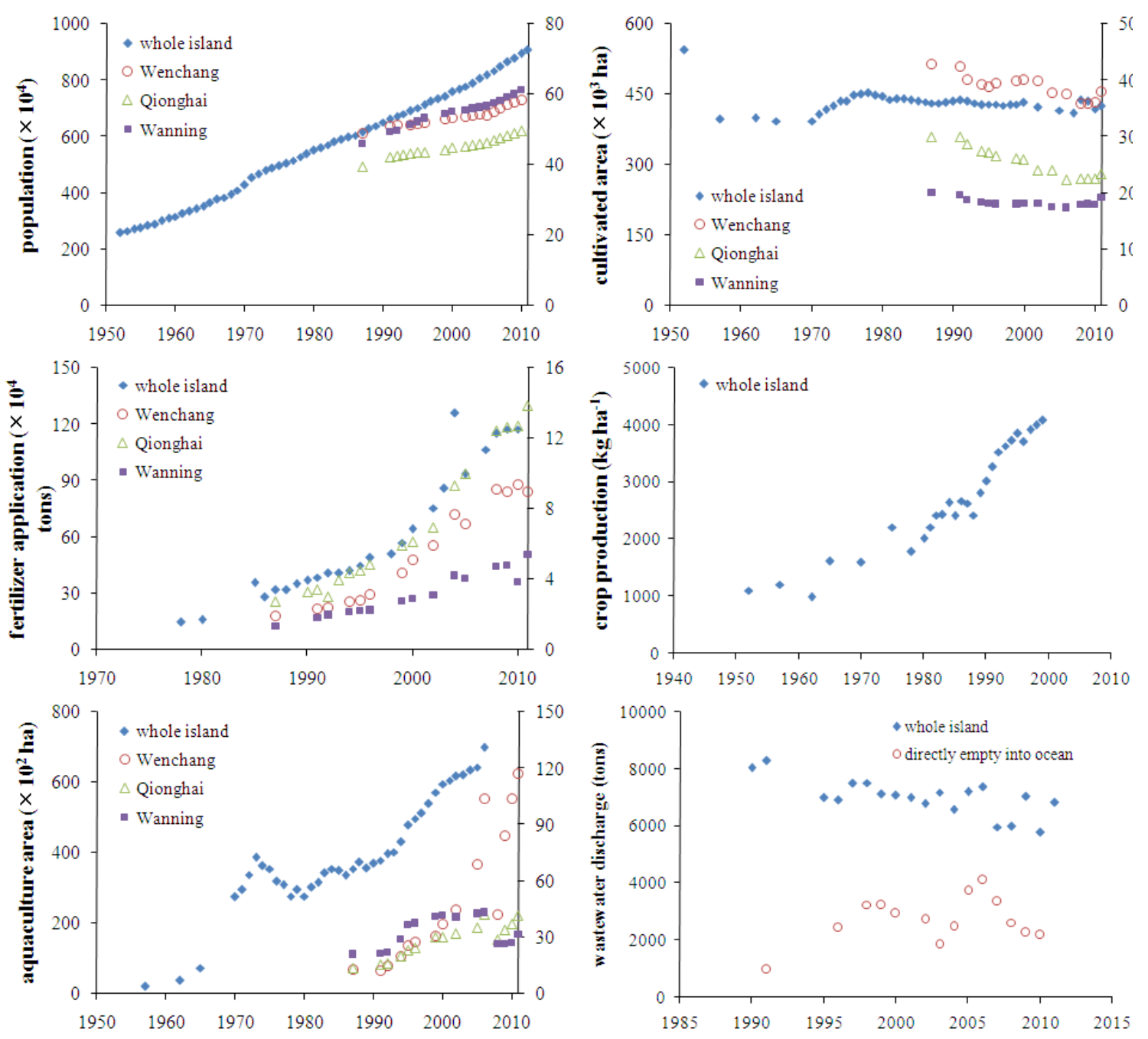

Fig. 5. Changes in population $\left(\times 10^{4}\right)$, cultivated area $\left(\times 10^{3}\right.$ ha), fertilizer application $\left(\times 10^{4}\right.$ tons $)$, crop production $\left(\mathrm{kg} \mathrm{ha}^{-1}\right)$, aquaculture area $\left(\times 10^{2} \mathrm{ha}\right)$ and wastewater discharge (tons) for the Hainan Island from 1952-2011, and the cities of Wenchang, Qionghai, and Wanning, 1987-2011. The left ordinate represents changes for the entire island, and the right ordinate represents changes for each city. The data are from the Hainan StatisticalY earbook for 1988, 1989, 1993, 1997, 2000, 2001, 2005, 2007, 2009, 2010,2011 and 2012.

which may explain the high nutrient concentrations found at station $\mathrm{XH} 2$. We found that DON was the dominant dissolved $\mathrm{N}$ component in the lagoons. The reason for that could be the many fish cages in the lagoons. Most of the dissolved nitrogen leaching from the feed, and shrimp feces was in organic rather than in organic forms (Burford and Williams, 2001). In addition, studies on total organic carbon and $\mathrm{N}$ contents in Shamei and XH lagoons indicated that in recent decades organic matter sources and nitrate loading were increasingly affected by human activities, and eutrophication was observed (Jia et al., 2012; Liu and Ge, 2012). Isotope analysis also indicated that sedimentation rate in XH Lagoon after 1988 was approximately twofold that in the previous decade because of anthropogenic activities, which has led to a significant increase in input of authigenic organic matter (Liu et al., 2007). Moreover, the aquaculture area has also in- creased, especially in Wenchang, where it has increased by a factor of 8.8 (Fig. 5). $\mathrm{N}$ and $\mathrm{P}$ fluxes can be enhanced by organic matter recycling in sediment introduced from aquaculture activities. Terrestrial inputs and aquaculture activities are important sources of nutrients in XH Lagoon. The input of large quantities of nutrients into a small lagoon (such as LYH Lagoon) through SGD could significantly affect its ecosystem. Hypoxia conditions were found in the inner part of LYH Lagoon in August 2009 (Sun, 2011).

The average concentrations of PP $(0.5-1.4 \mu \mathrm{M})$ in the WWE and WQE, and in XH and LYH lagoons were lower than in other estuaries worldwide, including the Delaware estuary (PP 1-2 $\mu$ M; Lebo and Sharp, 1993), the Humber estuary (PIP 14.3 $\mu$ M, POP $4.8 \mu \mathrm{M}$; Prastka and Malcolm, 1994), and the Changjiang estuary (PIP $2.00 \mu \mathrm{M}$, POP $1.02 \mu \mathrm{M}$; Wang et al., 2009). The lower concentrations found in this 
study may be related to low SPM content in the estuarine/lagoon systems. The PBSi concentrations in these systems (Table 2, Fig. 2) were comparable to those in the Aulne estuary (5.6-52 $\mu \mathrm{M}$; Ragueneau et al., 2005) and Drake Passage estuary $(4.24 \mu \mathrm{M}$; Turner et al., 2003), but higher than those in the Changjiang estuary (0.2-2.8 $\mu \mathrm{M}$; Liu et al., 2005) and Jiaozhou Bay (2.19 $\mu \mathrm{M}$; Luo et al., 2008). LSi levels along the eastern Hainan Island varied widely, and the average concentrations were approximately 1.1-13 times those in the Changjiang $(21.1 \pm 12.1 \mu \mathrm{M}$; Liu et al., 2009). In the WWE and WQE the PBSi and LSi concentrations were positively correlated with SPM, suggesting that the high concentrations of these nutrients in the lagoons may be related to a high weathering rate.

The relatively high nutrient concentrations in coastal waters close to the shore reflect considerable input from land, and suggest the effects of anthropogenic perturbation in the adjacent terrestrial areas. In addition, high nutrient concentrations associated with low salinity were apparent under high river discharge conditions $\left(278 \mathrm{~m}^{3} \mathrm{~s}^{-1}\right.$ in spring 2009 and $100 \mathrm{~m}^{3} \mathrm{~s}^{-1}$ summer 2007, Fig. 3a, e) indicating that river discharge might control the distribution of nutrients in coastal waters close to the shore. Several reports have suggested that river discharge is the main factor controlling matter transfer from land to sea, especially for small rivers (Ludwig et al., 2009; Han et al., 2012). Moreover, the seasonal variation of salinity, temperature and nutrients appeared to be closely coupled to monsoons. In summer, a plume of low salinity water with high nutrient levels extended northeast (Fig. 3a), may be under the combined effects of large river discharges and the Hainan Coastal Current, which travels from south to north (Chu et al., 1999). However, in spring, a nutrient-rich plume extended southwest under the effects of the WQ diluted water and northerly winds (Fig. 3c). In the long run, coastal ecosystems will be changed because of freshwater input with high nutrient levels, as has happened in other Chinese seas (Liu et al., 2009). Red tides have occurred along the east coastal of Hainan Island because of human activities (Pan et al., 2007).

Mangroves act as filters for river-derived nutrient pollutants in tropical and subtropical areas, protecting seagrass beds and coral reef ecosystems, and offering a potential means of reducing the export of pollutants from aquaculture (nutrients, pesticides, organic matter) (Jennerjahn, 2012). Mangrove sediments act as sinks for $N$ and $P$ in the WWE (Liu et al., 2011). Material temporarily trapped at low tide in the lagoon and the filtering effect of Bamen Bay could considerably reduce nutrient export to coastal waters (Zhang et al., 2013). However, $73 \%$ of the fringing riverine mangrove in the WWE has been lost since the 1960s and has been replaced by aquaculture ponds (Krumme et al., 2012). $6151 \mathrm{t} \mathrm{yr}^{-1}$ total organic carbon, $1292 \mathrm{t} \mathrm{yr}^{-1}$ total $\mathrm{N}$, and $51 \mathrm{tyr}^{-1}$ dissolved phosphate are exported from pond aquaculture to coastal and back-reef waters of the northeast Hainan Island (Herbeck et al., 2013). In addition, the WWE is a shallow water body with a short water residence time (approximately 7.8 days; Liu et al., 2011), and consequently heavy rainfall leading to high levels of river discharge can reduce the filtering effect of the estuary, leading to the release of material to the coastal environment. Because of typhoons, high SPM levels $\left(42 \mathrm{mg} \mathrm{L}^{-1}\right)$ and nutrients were found on the Dongjiao, Yelin and Tanmen reef flats (Herbeck et al., 2013; Roder et al., 2013), resulting in reduced light availability and increased sedimentation stress for reef-flat communities (Roder et al., 2013). In recent decades there has been increased anthropogenic organic matter transport from the WWE to the coastal sea, because of the degradation of mangrove forests and the expansion of aquaculture (Bao et al., 2013). Untreated municipal sewage from Wenchang is another potential source of dissolved nutrients and particulate organic matter entering the estuary (Herbeck et al., 2011). Thus, more nutrients would be transported to the ocean, contributing to the degradation of the coastal ecosystems.

Freshwater containing high nutrient concentrations directly enters the SCS through the narrow tidal inlet in the WQE (Fig. 1), especially when large quantities of river runoff occur in connection with heavy rain. Water residence time is only 0.2 days in the tidal inlet, and estuarine filtering can be readily disrupted. Approximately $60 \%$ of Shamei Lagoon (which is in the southern part of the WQE) is used for fish and shrimp ponds, and is connected to the sea through the tidal inlet. Isotope analysis has indicated that large inputs of $\mathrm{N}$ and $\mathrm{P}$ stimulate the growth of phytoplankton in the lagoon (Jia et al., 2012), and suggest that nutrient accumulation in the lagoon has led to eutrophication and changes to the ecological structure. Large quantities of nutrients will be input to coastal region through the tidal inlet. High nutrients plume appeared off the WQE (Fig. 3a, c) in our study. Nutrient enrichment in coastal waters often results in increased algal biomass, reducing water clarity and causing a loss of submerged macrophytes (Spivak et al., 2009). Hence, the coastal ecosystem off the WQE may be more significantly affected.

The morphology of XH Lagoon has been changed since 1972 through human interventions and total river discharge into the lagoon was reduced following the diversion of the Taiyanghe (TY) in 1972. In addition, the sand barrier has been continuously extended and the tidal inlet narrowed, and the tidal influence barely reaches the middle and southern parts of the lagoon. The northern part of the lagoon is more readily affected by tidal current and river runoff compared to the inner lagoon. Hence, the southern part of the lagoon has become a dead zone, where the water residence time is longer than 150 days (Gong et al., 2008). Total organic carbon and total $\mathrm{N}$ levels in sediment indicate that authigenic organic matter significantly increased in the lagoon after 1988 because of aquaculture activities, and that large nutrient inputs have deteriorated the water quality of XH Lagoon (Liu et al., 2007). High nutrient levels are maintained in XH Lagoon, resulting in algal or phytoplankton blooms and depleted oxygen; this has been confirmed by isotope analysis (Liu and Ge, 
2012). Furthermore, the lagoon entrance mouth has narrowed from $140 \mathrm{~m}$ to less than $30 \mathrm{~m}$ in the last $30 \mathrm{yr}$ because of land reclamation and cage culture in the tidal inlet (Wang et al., 2003). The lagoon formed a deposit and was shallow. This caused serious inundation in October 2000, when a violent typhoon hit the island (Yu et al., 2002; Wang et al., 2003). Large quantities of materials from the lagoon transport to the ocean company with rainfall. Additionally, the TY empties directly into the SCS following the diversion. A study in August 2008 showed that $7.7 \times 10^{4} \mathrm{~mol} \mathrm{day}^{-1}$ of DIN, $0.2 \times 10^{3} \mathrm{~mol} \mathrm{day}^{-1}$ of $\mathrm{PO}_{4}^{3-}$, and $31.5 \times 10^{4} \mathrm{~mol} \mathrm{day}^{-1}$ of dissolved silicate transported directly to the SCS in the TY, affecting coastal ecosystems.

Coastal erosion may be another source of materials entering coastal waters and transported by longshore drift and coastal currents. The coastline is receding by approximately $10 \mathrm{~m}$ per year (Wang, 1998), and this may be a consequence of sea level rise, which, based on data for 1977-1978 and 1980-1993, has been estimated to be of $0.92 \mathrm{~mm} \mathrm{yr}^{-1}$ along the eastern coast (Wang, 2002). Furthermore, the coral reef (approximately 500-1000 $\mathrm{m}$ wide) has been subject to serious degradation because of human activities in the past $20 \mathrm{yr}$, resulting in shoreline erosion. The coastal barrier in our study region is still growing, and the lagoons may be closed to the sea in the future. Nutrient dynamics will be affected by these terrain changes.

Studies of SGD along the eastern coast of Hainan Island are very limited. Nutrient budgets based on box models indicated that SGD is important source of nutrient to the WWE and WQE (Liu et al., 2011; Li et al., 2013). Horizontal eddy diffusion fluxes of nutrients from coast to offshore area were estimated based on nutrient gradients and horizontal eddy diffusion coefficient values, were estimated in August 2007 using ${ }^{228} \mathrm{Ra}$ (Su et al., 2011b). This analysis showed that over 6 months $2.3 \times 10^{8} \mathrm{~mol}$ of $\mathrm{N}, 1.5 \times 10^{7} \mathrm{~mol}$ of $\mathrm{P}$ and $5.1 \times 10^{8} \mathrm{~mol}$ of $\mathrm{Si}$ were transported from the study area to the SCS, $100 \mathrm{~km}$ off the coastline. Li et al. (2012) reported that spatially discrete and temporally episodic nutrient fluxes, caused by physical phenomena such as eddies, fronts and filaments, could have an important effect in regions where phytoplankton growth is nutrient limited.

Moreover, the WQE, and $\mathrm{XH}$ and $\mathrm{LYH}$ lagoons were all separated from the ocean by sand barriers, which continue to expand under the action of southeasterly winds that transport sediment from south to north (Wang and Li, 2006). Due to the combined effects of human activities and natural factors, the lagoons can be transformed into closed water bodies, resulting in eutrophication because of high nutrient levels and alterations to these small, dynamic and fragile ecosystems. Such changes could result in changes to the coastal system associated with changed riverine fluxes, activities such as mariculture, aeolian input (dust), and potentially circulation patterns (Kress et al., 2005).

\subsection{Nutrient fluxes from the lagoons to the SCS}

Nutrient fluxes from the lagoons to the SCS were estimated as the sum of the net residual flux $\left(V_{\mathrm{R}} C_{\mathrm{R}}\right)$ and the mixing flux $\left(V_{\mathrm{X}} C_{\mathrm{X}}\right)$. Nutrient fluxes were a factor of 392-1878 of the riverine input $\left(F_{\text {model }}=V C_{\mathrm{Q}}\right)$ to $\mathrm{LYH}$ Lagoon due to the influence of SGD. With the exception of $\mathrm{PO}_{4}^{3-}$ and DON, nutrient fluxes to the SCS were lower than riverine input to XH Lagoon. This might be related to aquaculture activities, which decreased the tidal flushing efficiency. As a result, large quantities of nutrients were retained in XH Lagoon.

Total nutrient fluxes from the estuaries and lagoons to coastal region were calculated based on nutrient budgets. The results showed that DON represented $29 \%$ of TDN, DOP was $40 \%$ of TDP, and PP accounted for $48 \%$ of TP. The potential for DON and DOP to act as nutrient sources for primary producers when phytoplankton growth was limited has long been recognized (Engeland et al., 2010; Huang et al., 2005). This suggests that the transport of large quantities of both dissolved organic nitrogen and phosphate from the lagoons to the SCS is important, and might determine the impact on receiving coastal ecosystems, especially within the coral reef region.

The flux ratios of DIN : $\mathrm{PO}_{4}^{3-}$ and DSi:DIN were approximately 40 and 3.0, respectively. The loading ratio exceeded the Redfield ratio, demonstrating that the ecosystem in the coastal zone of the SCS would be affected by nutrient transport. Total $\mathrm{N}$ and dissolved phosphate transported to the coastal region through effluent from shrimp ponds accounted for $22 \%$ of nitrogen fluxes and $15 \%$ of phosphorus fluxes. Primary production in the continental shelf region $(<200 \mathrm{~m})$ of the SCS would be $602.3 \times 10^{6} \mathrm{tC} \mathrm{yr}^{-1}$ based on data for two seasons (summer and winter) (Ning et al., 2004). Based on the Redfield stoichiometric ratio $(\mathrm{C}: \mathrm{N}: \mathrm{P}=106: 16: 1)$, $10.7 \times 10^{7} \mathrm{tyr}^{-1}$ of $\mathrm{N}$ and $6.6 \times 10^{6} \mathrm{tyr}^{-1}$ of phosphate would be assimilated by primary producers. The lagoons contributions to the continental shelf region $(<200 \mathrm{~m})$ of the SCS could account for $0.005 \%$ of nitrogen and $0.005 \%$ of phosphate. The contribution of terrigenous nutrient input to primary production of the SCS is limited.

SGD, which is the major source of nutrients entering LYH Lagoon, was not included in water budgets for XH Lagoon. An estimate of SGD in XH Lagoon based on SGD observations in the WWE $\left(3.4 \pm 5.0 \mathrm{~m} \mathrm{~s}^{-1}\right.$; Su et al., 2011) suggests it accounts for approximately $13 \%$ of the freshwater discharge into the lagoon. Hence, if SGD is considered, $\mathrm{XH}$ Lagoon would be a sink of all nutrients. Estimation of SGD for XH Lagoon based on SGD in LYH Lagoon suggests it accounts for a factor of approximately 1.8 that of the freshwater discharge into the lagoon. SGD would be the major source of nutrients in XH Lagoon. Furthermore, XH Lagoon is an important site for aquatic products and is the fishing port of Wanning (Gong et al., 2008), but aquaculture effluents were not included in the water budgets for this lagoon or LYH Lagoon. The area of Wanning used for marine aquaculture 
increased from 233 ha in 1989 to 1495 ha in 2008 (Hainan Statistical Yearbook, 1992, 2009). Uncertainties in the estimation of the water budgets in XH Lagoon could be up to $25 \%$ if aquaculture effluents were considered as in the WWE $\left(210 \times 10^{6} \mathrm{~m}^{3} \mathrm{yr}^{-1}\right.$; Liu et al., 2011), and could be up to $14 \%$ for $\mathrm{LYH}$ Lagoon. Hence, $\mathrm{PO}_{4}^{3-}$ and DON budgets in $\mathrm{XH}$ Lagoon would reverse a source to a sink if SGD and aquaculture effluents were considered, while the $\mathrm{NO}_{2}^{-}$ budget would switch from a source to a sink if aquaculture effluents were considered in LYH Lagoon. More nutrients would be found to be stored in XH and LYH lagoons if SGD and aquaculture effluents were taken into account. In addition, domestic sewage and agriculture pollutants (e.g., pesticides and fertilizers) were not included in the water budgets. Sewage is an important source of nutrients for freshwater and coastal marine ecosystems (Bouwman et al., 2013). Therefore, more studies on nutrient transport related to submarine groundwater, wastewater and aquaculture are needed.

\subsection{Role of typhoon in biogeochemistry of nutrients}

Typhoons are an important natural phenomenon that can affect the biogeochemistry of nutrients in coastal zones. Nutrient biogeochemistry would be changed in a short time, especially in small rivers during storm events. The eastern Hainan Island has the highest precipitation on the island with increasing rate at $2.228 \mathrm{~mm} \mathrm{yr}^{-1}$ (Wang et al., 2006), and typhoon-induced rainfall can account for $36 \%$ of total annual rainfall (Wang, 1985). The effect of land-derived anthropogenic nutrients can be reinforced by typhoon-related rainfall (Jennerjahn, 2012). Increased N and P loading in rivers can enhance rates of photosynthetic and heterotrophic productivity, resulting in fundamental changes to aquatic food webs (Bouwman et al., 2013).

Typhoon Damrey made landfall on the eastern Hainan Island on 25 September 2005, with $>300 \mathrm{~mm}$ of rainfall occurring on 26 September (Zheng and Tang, 2007). The daily water discharge from the WQ increased from $64.4 \mathrm{~m}^{3} \mathrm{~s}^{-1}$ to $278 \mathrm{~m}^{3} \mathrm{~s}^{-1}$ following the first rainfall event (approximately $118 \mathrm{~mm}$ ) in April 2009. Typhoon Kammuri made landfall along the south coast of China in the western part of the Guangdong province on 6 August 2008. On 7 August 2008 it passed the study area in a distance of approximately $200 \mathrm{~km}$. The daily water discharge of Nandu River, which empties into Qiongzhou Strait, increased from $249 \mathrm{~m}^{3} \mathrm{~s}^{-1}$ on 6 August 2008 to $1615 \mathrm{~m}^{3} \mathrm{~s}^{-1}$ on 7 August. The WQ discharge gradually increased over the following few days and peaked at $220 \mathrm{~m}^{3} \mathrm{~s}^{-1}$ five days after the typhoon. Freshwater (salinity $=0$ ) reached the estuary mouth following the typhoon, where, prior to the typhoon, salinity was approximately 31 in the WQE. SPM concentrations increased from $3.05-21.5 \mathrm{mg} \mathrm{L}^{-1}$ to $12.0-23.3 \mathrm{mg} \mathrm{L}^{-1}$ in the estuary. Nutrient fluxes from the WQE to the SCS following the typhoon in August 2008 exceeded the pre-typhoon fluxes by a factor of 2.6-4.7. River discharges, SPM and nutrients derived from agriculture, aquaculture and urban effluents exported into coastal water also increased in the WWE following the typhoon (Herbeck et al., 2011; Liu et al., 2011), and the coral reef was affected by the large nutrient and SPM loads (Roder et al., 2013). A violent typhoon made landfall at Wanning in October 2000. Terrigenous material from towns, cultivated areas and fish ponds adjacent to XH Lagoon was transported to the sea, accompanied by typhoon-induced rainfall (Tian and $\mathrm{Li}, 2007)$. These results show that the influence of human activities is strengthened by typhoon phenomena. If typhoons, which, like Damrey and Kammuri, are often accompanied by heavy rainfall directly made landfall in the study area, large fluvial discharge is caused. Large quantities of dissolved and particulate materials must be exported to coastal waters as a result. Observations in August 2007 took place following a typhoon event; low salinity (22.0) with high nutrients $\left(\mathrm{NO}_{3}^{-}: 25.0 \mu \mathrm{M}\right)$ appeared in coastal waters off the WQE (Fig. 3a). In addition, atmospheric deposition during normal typhoon events (rainfall $300 \mathrm{~mm}$; Liu et al., 2011) in the study coastal region could represent approximately 11 , 17 and $10 \%$ of the annual atmospheric deposition of DIN, $\mathrm{PO}_{4}^{3-}$ and DSi, respectively. The offshore waters are more easily affected by typhoon rainfall than by normal rainfall discharge, which tends to be confined to the coastal shelf.

Upwelling is a significant source of the nutrients (particularly $\mathrm{PO}_{4}^{3-}$ ) that enter the shelf ecosystem and affect phytoplankton succession (Liu et al., 2000; Ou et al., 2008). Upwelling events occur frequently during the summer monsoon period along the eastern Hainan shelf (Su et al., 2011a). Additionally, typhoons potentially affecting Hainan Island mainly occur from May to November (Ren et al., 2002; Liu et al., 2011). The combination of a typhoon and upwelling could enhance phytoplankton biomass production by causing transport of nutrient-rich water from estuaries to offshore and bringing deep waters to surface along the eastern Hainan coast. Zheng and Tang (2007) reported that two phytoplankton blooms were triggered by Typhoon Damrey which passed through the Hainan Island during September 2005 due to nutrients transport from land and below to the surface water via upwelling.

Tropical storms are likely to increase in strength, duration, destructiveness and frequency in response to global climate change (Knutson et al., 2010; Kaiser et al., 2013). For coastal waters this will result in more frequent short-term changes to freshwater and nutrient inputs, especially in the study area where the water residence time is so short and easily interrupted. Increased hurricane/typhoon activity may enhance silicate weathering rates and exacerbate current sediment delivery loads, thereby increasing POC delivery and burial in mountainous rivers (Goldsmith et al., 2008). Hence, more research on the influence of typhoons is needed. 


\section{Conclusions}

This study has provided data for dissolved and particulate nutrient concentrations along the eastern Hainan Island during both the wet and the dry season. Under the combined effects of natural processes and human activities (including agriculture, aquaculture and urban wastewater), large quantities of nutrients are transported to, and affect, the coastal ecosystems.

All nutrients showed seasonal variation and decreased from rivers towards the coast. The nutrients in rivers were mainly affected by agriculture; they were enriched with DIN and $\mathrm{DSi}$, and depleted in $\mathrm{PO}_{4}^{3-}$. As a result of human activities the DIN areal yields were apparently higher than the average yields reported for large tropical and nontropical rivers. The $\mathrm{PO}_{4}^{3-}$ concentrations and areal yields in rivers were lower than those reported for other tropical rivers. The dissolved silicate levels and areal yields were higher than in other tropical river systems worldwide because of rock type and the high rate of chemical weathering. TDP was dominated by DOP, and the PP contribution to TP was significant.

Nutrient processes in the lagoons were significantly affected by riverine inputs, aquaculture activities and groundwater. The estuaries and lagoons have short response times to flood events, and large quantities of nutrients were transported to the eastern coast of Hainan Island. A simple steadystate box model was used to construct nutrient budgets to investigate nutrient biogeochemical process along the eastern coast of Hainan Island. The model's results indicate that riverine input is the major source of nutrients to the WWE, $\mathrm{WQE}$ and $\mathrm{XH}$ Lagoon, and GW is the major source of nutrient input to LYH Lagoon. Particularly riverine nitrogen and phosphorus export into coastal areas from anthropogenic land-based sources. Most nutrients would be buried in the sediment or transformed into other forms in the lagoons. Nutrient ratios showed that the potential limiting nutrient for phytoplankton growth within the coral reef region was $\mathrm{P}$ because of large quantities of nitrogen inputs from terrestrial, while $\mathrm{N}$ was the limiting nutrient for phytoplankton growth in the coastal waters of the northern South China Sea. Nutrient inputs to the coastal ecosystem increased with typhooninduced runoff of rainwater, elucidating the important impact of typhoons on small tropical rivers.

\section{Supplementary material related to this article is available online at http://www.biogeosciences.net/11/481/ 2014/bg-11-481-2014-supplement.pdf.}

Acknowledgements. This study was supported by the LANCET (Land-Sea Interactions along Coastal Ecosystems of Tropical China: Hainan) and was funded by the Ministry of Science and Technology of the People's Republic of China (2007DFB20380, 2014CB441502) within the framework of a Chinese-German joint study and the Chinese Natural Sciences Foundation (40925017, 41376086). The authors thank their colleagues at the Center for Tropical Marine Ecology, the Hainan Provincial Marine Development Plan and Design Research Institute, Second Institute of Oceanography, East China Normal University, and the Ocean University of China for their help with field investigations.

Edited by: H. Liu

\section{References}

Alongi, D. M. (Eds): Coastal Ecosystem Processes, CRC Press, 419 pp., 1998.

Aspila, K. I., Agemian, H., and Chau, A. S. Y.: A semiautomatic method for the determination of inorganic, organic and total Phosphorus in sediment, Analyst, 101, 187-197, 1976.

Bao, H. Y., Wu, Y., Unger, D., Du, J. Z., Herbeck, L. S., and Zhang, J.: Impact of the conversion of mangroves into aquaculture ponds on the sedimentary organic matter composition in a tidal flat estuary (Hainan Island, China), Cont. Shelf Res., 57, 82-91, 2013.

Bouwman, A. F., Bierkens, M. F. P., Griffioen, J., Hefting, M. M., Middelburg, J. J., Middelkoop, H., and Slomp, C. P.: Nutrient dynamics, transfer and retention along the aquatic continuum from land to ocean: towards integration of ecological and biogeochemical models, Biogeosciences, 10, 1-22, doi:10.5194/bg10-1-2013, 2013.

Brzezinski, M. A.: The Si/C/N ratios of marine diatoms: interspecific variability and the effect of some environmental variables, J. Phycol., 21, 345-357, 1985.

Burford, M. A. and Williams, K. C.: The fate of nitrogenous waste from shrimp feeding, Aquaculture, 198, 79-93, 2001.

Cai, W. J., Dai, M. H.,Wang, Y. S., Zhai, W. D., Huang, T., Chen, S. T., Zhang, F., Chen, Z. Z., and Wang, Z. H.: The biogeochemistry of inorganic carbon and nutrients in the Pearl River estuary and adjacent Northern South China Sea, Cont. Shelf Res., 24, 13011319, 2004.

Chai, F., Xue, H. J., and Shi, M. C.: Upwelling east of Hainan Island. Oceanography in China (13), Ocean Press, Beijing, 105116, 2001 (in Chinese with English abstract).

Chen, Y.L.L. and Chen, H. Y.: Seasonal dynamics of primary and new production in the northern South China Sea: The significance of river discharge and nutrient advection, Deep-Sea Res. Pt. I, 53, 971-986, 2006.

Chu, P. C., Edmons, N. L., and Fan, C.: Dynamical mechanisms for the South China Sea seasonal circulation and thermohaline variabilitie, J. Phys. Oceanogr., 29, 2971-2989, 1999.

Conley, D. J.: River contribution of biogenic silica to the oceanic silica budget, Limnol. Oceanogr., 42, 774-777, 1997.

Cornelis, J.-T., Delvaux, B., Georg, R. B., Lucas, Y., Ranger, J., and Opfergelt, S.: Tracing the origin of dissolved silicon transferred from various soil-plant systems towards rivers: a review, Biogeosciences, 8, 89-112, doi:10.5194/bg-8-89-2011, 2011.

Dürr, H. H., Laruelle, G. G., van Kempen, C. M., Slomp, C. P., Meybeck, M., and Middelkoop, H.: Worldwide typology of nearshore coastal systems: defining the estuarine filter of river inputs to the oceans, Estuar. Coast., 34, 441-458, 2011.

Engeland, T. V., Soetaert, K., Knuijt, A., Laane, R. W. P. M., and Middelburg, J. J.: Dissolved organic nitrogen dynamics in the 
North Sea: A time series analysis (1995-2005), Estuar. Coast. Shelf S., 89, 31-42, 2010.

Fang, T. H.: Phosphorus speciation and budget of the East China Sea, Cont. Shelf Res., 24, 1285-1299, 2004.

Gattuso, J. P., Frankignoulle, M., and Wollast, R.: Carbon and carbonate metabolism in coastal aquatic ecosystems, Annu. Rev. Ecol. Syst., 29, 405-434, 1998.

Ge, C. D., Slaymaker, O., and Pedersen, T. F.: Change in the sedimentary environment of Wanquan river Estuary, Hainan Island, China, Chinese Sci. Bull., 48, 2357-2361, 2004 (in Chinese with English abstract).

Goldsmith, S. T., Carey, A. E., Lyons, W. B., Kao, S. J., Lee, T. Y., and Chen, J.: Extreme storm events, landscape denudation, and carbon sequestration: Typhoon Mindulle, Choshui River, Taiwan, Geology, 36, 483-486, 2008.

Gong, W. P., Shen, J., and Jia, J. J.: The impact of human activities on the flushing properties of a semi-enclosed lagoon: Xiaohai, Hainan, China, Mar. Environ. Res., 65, 62-76, 2008.

Gordon, D. C., Boudreau, P. R., Mann, K. H., Ong, J.-E., Silvert, W. L., Smith, S. V., Wattayakorn, G., Wulff, F., and Yanagi, T.: LOICZ Biogeochemical Modeling Guidelines. LOICZ Reports and Studies (5), LOICZ, Texel, The Netherlands, 96 pp., 1996.

Halpern, B. S., Walbridge, S., Selkoe, K. A., Kappel, C. V., Micheli, F., D’Agrosa, C., Bruno, J. F., Casey, K. S., Ebert, C., Fox, H. E., Fujita, R., Heinemann, D., Lenihan, H. S., Madin, E. M. P., Perry, M. T., Selig, E. R., Spalding, M., Steneck, R., and Watson, R.: A global map of human impacts on marine ecosystems, Science, 319, 948-952, 2008.

Han, A. Q., Dai, M. H., Kao, S. J., Gan, G. P., Li, Q., Wang, L. F., Zhai, W. D., and Wang, L.: Nutrient dynamics and biological consumption in a large continental shelf system under the influence of both a river plume and coastal upwelling, Limnol. Oceanogr., 57, 486-502, 2012.

Han, Y. S., Fu, C. Q., Tang, Q. J., and Xu, J.: The influence of nitrogen application to yield of rice and nitrogen utilization in tropical region, Guangdong Agri. Sci., 37, 102-103, 2010 (in Chinese).

Hansen, H. P. and Koroleff, F.: Determination of nutrients, in: Methods of Seawater Analysis, edited by: Grasshoff, K., Kremling, K., and Ehrhardt, M., Weinheim, New York, Chiester, Brisbane, Singapore, Toronto, WILEY-VCH, 159-228, 1999.

Herbeck, L. S., Unger, D., Krumme, U., Liu, S. M., and Jennerjahn, T. C.: Typhoon-induced precipitation impact on nutrient and suspended matter dynamics of a tropical estuary affected by human activities in Hainan, China, Estuar. Coast. Shelf S., 93, 375-388, 2011.

Herbeck, L. S., Unger, D., Wu, Y., and Jennerjahn, T. C.: Effluent, nutrient and organic matter export from shrimp and fish ponds causing eutrophication in coastal and back-reef waters of NE Hainan, Tropical China, Cont. Shelf Res., 57, 92-104, 2013.

Huang, B. Q., Ou, L. J., Hong, H. S., Luo, H. W., and Wang, D. Z.: Bioavailability of dissolved organic phosphorus compounds to typical harmful dinoflagellate Prorocentrum donghaiense $\mathrm{Lu}$, Mar. Pollut. Bull., 51, 838-844, 2005.

Jennerjahn, T. C.: Biogeochemical response of tropical coastal systems to present and past environmental change, Earth-Sci. Rev., 114, 19-41, 2012.

Jennerjahn, T. C., Ittekkot, V., Klöpper, S., Adi, S., Nugroho, S. P., Sudiana, N., Yusmal, A., and Prihartanto, B. G. -H.: Biogeochemistry of a tropical river affected by human activities in its catchment: Brantas River estuary and coastal waters of Madura Strait, Java, Indonesia, Estuar. Coast. Shelf S., 60, 503-514, 2004.

Jennerjahn, T. C., Soman, K., Ittekkot, V., Nordhaus, I., Sooraj, S., Priya, R. S., and Lahajnar, N.: Effect of land use on the biogeochemistry of dissolved nutrients and suspended and sedimentary organic matter in the tropical Kallada River and Ashtamudi estuary, Kerala, India, Biogeochemistry, 90, 29-47, 2008.

Jennerjahn, T. C., Nasir, B., and Pohlenga, I.: Spatio-temporal variation of dissolved inorganic nutrients related to hydrodynamics and land use in the mangrove-fringed Segara Anakan Lagoon, Java, Indonesia, Reg. Environ. Change, 9, 259-274, 2009.

Ji, T., Du, J. Z., Moore, W. S., Zhang, G. S., Su, N., and Zhang, J.: Nutrient inputs to a lagoon through submarine groundwater discharge: The case of Laoye Lagoon, Hainan, China, J. Mar. Syst., 111-112, 253-262, 2013.

Jia, J. J., Gao, J. H., Liu, Y. F., Gao, S., and Yang, Y.: Environmental changes in Shamei Lagoon, Hainan Island, China: Interactions between natural processes and human activities, J. Asian Earth Sci., 52, 158-168, 2012.

Jing, Z. Y., Qi, Y. Q., Hua, Z. L., and Zhang, H.: Numerical study on the summer upwelling system in the northern continental shelf of the South China Sea, Cont. Shelf Res., 29, 467-478, 2009.

Kaiser, D., Unger, D., Qiu, G. L., Zhou, H. L., and Gan, H. Y.: Natural and human influences on nutrient transport through a small subtropical Chinese estuary, Sci. Total Environ., 450/451, 92107,2013

Knutson, T. R., McBride, J. L., Chan, J., Emanuel, K., Holland, G., Landsea, C., Held, I., Kossin, J. P., Srivastava, A. K., and Sugi, M.: Tropical cyclones and climate change, Nat. Geosci., 3, $157-$ 163,2010

Kress, N., Thingstad, T. F., Pitta, P., and Psarra, S.: Effect of P and N addition to oligotrophic Eastern Mediterranean waters influenced by near-shore waters: A microcosm experiment, Deep-Sea Res. Pt. II, 52, 3054-3073, 2005.

Krumme, U., Herbeck, L. S., and Wang, T. C.: Tide- and rainfallinduced variations of physical and chemical parameters in a mangrove-depleted estuary of East Hainan (South China Sea), Mar. Environ. Res., 82, 28-39, 2012.

Lebo, M. E. and Sharp, J. H.: Distribution of phosphorus along the Delaware, an urbanized coastal plain estuary, Estuar. Coast., 16, 290-301, 1993.

Li, D.: The Study on the HydroChemical Characteristics and the Flux to the Sea About Rivers in the East of China, Master Thesis, East China Normal University Press, Shanghai, China, 106 pp., 2009 (in Chinese).

Li, K. Z., Yin, J. Q., Huang, L. M., Lian, S. M., Zhang, J.L., and Liu, C. G.: Monsoon-forced distribution and assemblages of appendicularians in the northwestern coastal waters of South China Sea, Estuar. Coast. Shelf S., 89, 145-153, 2010.

Li, K. Z., Yin, J. Q., Huang, L. M., Zhang, J. L., Lian, S. M., and Liu, C. G.: Distribution and abundance of thaliaceans in the northwest continental shelf of South China Sea, with response to environmental factors driven by monsoon, Cont. Shelf Res., 31, 979989, 2011a.

Li, Q. P., Franks, P. J. S., Ohman, M. D., and Landry, M. R.: Enhanced nitrate fluxes and biological processes at a frontal zone in the southern California current system, J. Plankton Res., 34, 790-801, doi:10.1093/plankt/fbs006, 2012. 
Li, R. H., Liu, S. M., Zhang, G. L., Ren, J. L., and Zhang, J.: Biogeochemistry of nutrients in an estuary affected by human activities: The Wanquan River estuary, eastern Hainan Island, China, Cont. Shelf Res., 57, 18-31, 2013.

Li, Y. W., Liu, S. M., Zhu, Z. Y., Zhang, G. L., Li, R. H., and Zhang, J.: Distribution and budget of particulate of phosphorus and silica in Wanquanhe River estuary, Acta Oceanol. Sinica, 33, 180-188, $2011 b$ (in Chinese with English abstract).

Liu, K. -K., Tang, T. Y., Gong, G. -C., Chen, L. -Y., and Shiah, F. $\mathrm{K}$. : Cross-shelf and along-shelf nutrient fluxes derived from flow fields and chemical hydrography observed in the southern East China Shelf off northern Taiwan, Cont. Shelf Res., 20, 493-523, 2000.

Liu, S. M., Zhang, J., Chen, H. T., and Zhang, G. S.: Factors influencing nutrient dynamics in the eutrophic Jiaozhou Bay, North China, Prog. Oceanogr., 66, 66-85, 2005.

Liu, S. M., Li, X. N., Zhang, J., Wei, H., Ren, J.L., and Zhang, G. L.: Nutrient dynamics in Jiaozhou Bay, Water Air Soil Pollut: Focus, 7, 625-643, 2007.

Liu, S. M., Ye, X. W., Zhang, J., Zhang, G. S., and Wu, Y.: The silicon balance in Jiaozhou Bay, North China, J. Marine Syst., 74, 639-648, 2008.

Liu, S. M., Hong, G.-H., Zhang, J., Ye, X. W., and Jiang, X. L.: Nutrient budgets for large Chinese estuaries, Biogeosciences, 6 , 2245-2263, 2009,

http://www.biogeosciences.net/6/2245/2009/.

Liu, S. M., Li, R. H., Zhang, G. L., Wang, D. R., Du, J. Z., Herbeck, L. S., Zhang, J., and Ren, J.L.: The impact of anthropogenic activities on nutrient cycling dynamics in the tropical Wenchanghe and Wenjiaohe Estuary and Lagoon system in East Hainan, China, Mar. Chem., 125, 49-68, 2011.

Liu, X. J. and Ge, C. D.: Spatial and temporal variations of sedimented organic matter in Xiaohai Lagoon, Hainan Island, Acta Oceanol. Sin., 31, 74-86, 2012.

Liu, X. J., Ge, C. D., Chen, P. P., and Shi, X. D.: Anthropogenic impact on the sedimentary environment of Xiaohai Lagoon, Hainan Island, Environ. Chem., 26, 384-387, 2007 (in Chinese with English abstract).

Ludwig, W., Dumont, E., Meybeck, M., and Heussner, S.: River discharges of water and nutrients to the Mediterranean and Black Sea: Major drivers for ecosystem changes during past and future decades?, Prog. Oceanogr., 80, 199-217, 2009.

Luo, X., Liu, S. M., Zhang, J., Ye, X. W., Zhang, G. S., Ren, J. L., and Zhang, G. L.: A study on particulate biogenic silica and other factors in Jiaozhou Bay, Periodical of Ocean University of China, 38, 627-634, 2008 (in Chinese with English abstract).

Mao, L. M., Zhang, Y.L., and Bi, H.: Modern pollen deposits in coastal mangrove swamps from northern Hainan Island, China, J. Coast. Res., 22, 1423-1436, 2006.

Meunier, J. D., Braun, J. J., Riotte, J., Kumar, C., and Sekhar, M.: Importance of weathering and human perturbations on the riverine transport of Si, Appl. Geochem., 26, S360-S362, 2011.

Ning, X., Cai, F., Xue, H., Cai, Y., Liu, C., and Shi, J.: Physicalbiological oceanographic coupling influencing phytoplankton and primary production in the South China Sea, J. Geophys. Res., 109, C10005, doi:10.1029/2004JC002365, 2004.

Ou, L. J., Wang, D., Huang, B. Q., Qi, Y. Z., and Lu, S. H.: Comparative study of phosphorus strategies of three typical harmful algae in Chinese coastal waters, J. Plankton Res., 30, 1007-1017, 2008.

Pan, Y. Z., Song, F., Gao, J. X., Jin, Y., Fu, G. J., and Ye, N. L.: Study on aquatic ecological pollution in inshore areas in Hainan Province, Res. Environ. Sci., 20, 58-63, 2007 (in Chinese with English abstract).

Prastka, K. E. and Malcolm, S. J.: Particulate phosphorus in the Humber estuary, Aquat. Ecol., 28, 397-403, 1994.

Qiu, D. J., Huang, L. M., Zhang, J. L., and Lin, S. J.: Phytoplankton dynamics in and near the highly eutrophic Pearl River Estuary, South China Sea, Cont. Shelf Res., 30, 177-186, 2010.

$\mathrm{Qu}$, H. J. and Kroeze, C.: Past and future trends in nutrients export by rivers to the coastal waters of China, Sci. Total Environ., 408, 2075-2086, 2010.

Ragueneau, O., Savoye, N., Del Amo, Y., Cotton, J., Tardiveau, B., and Leynaert, A.: A new method for the measurement of biogenic silica in suspended matter of coastal waters: using $\mathrm{Si}$ :Al ratios to correct for the mineral interference, Cont. Shelf Res., 25, 697710, 2005.

Ren, F., Gleason, B., and Easterling, D.: Typhoon impacts on China's precipitation during 1957-1996, Adv. Atmos. Sci., 19, 943-952, 2002.

Roder, C., Wu, Z. J., Richter, C., and Zhang, J.: Coral reef degradation and metabolic preformance of the scleractinian coral Porites lutea under anthropogenic impact along the NE coast of Hainan Island, South China Sea, Cont. Shelf Res., 57, 123-131, 2013.

Savchuk, O. P.: Resolving the Baltic Sea into seven subbasins: N and P budgets for 1991-1999, J. Mar. Syst., 56, 1-15, 2005.

Seitzinger, S. P., Harrison, J. A., Dumont, E., Beusen, A. H. W., and Bouwman, A. F.: Sources and delivery of carbon, nitrogen, and phosphorus to the coastal zone: an overview of global nutrient export from watersheds (NEWS) models and their application, Global Biogeochem. Cy., 19, GB4S01, doi:10.1029/2005GB002606, 2005.

Smith, J., Burford, M. A., Revill, A. T., Haese, R. R., and Fortune, J., Effect of nutrient loading on biogeochemical processes in tropical tidal creeks, Biogeochemistry, 108, 359-380, 2012.

Smith, S. V., Swaney, D. P., Talaue-McManus, L., Bartley, J. D., Sandhei, P. T., McLaughlin, C. J., Dupra, V. C., Crossland, C. J., Buddemeier, R. W., Maxwell, B. A., and Wulff, F.: Humans, hydrology, and the distribution of inorganic nitrogen loading to the ocean, Bioscience, 53, 235-245, 2003.

Spivak, A. C., Canuel, E. A., Duffy, J. E., and Richardson, J. P.: Nutrient enrichment and food web composition affect ecosystem metabolism in an experimental seagrass habitat, PLoS ONE, 4, e7473, doi:10.1371/journal.pone.0007473, 2009.

Statistical Bureau of Hainan Province, Survey Office of National Bureau of Statistics in Hainan: Hainan Statistical Yearbook, China Statistic Press, Beijing, 654 pp., 1992 (in Chinese).

Statistical Bureau of Hainan Province, Survey Office of National Bureau of Statistics in Hainan: Hainan Statistical Yearbook, China Statistic Press, Beijing, 461 pp., 2009 (in Chinese).

Statistical Bureau of Hainan Province, Survey Office of National Bureau of Statistics in Hainan: Hainan Statistical Yearbook, China Statistic Press, Beijing, 460 pp., 2010 (in Chinese).

$\mathrm{Su}$, J. and Pohlmann, T.: Wind and topography influence on an upwelling system at the eastern Hainan coast, J. Geophys. Res., 114, C06017, doi:10.1029/2008JC005018, 2009. 
Su, J., Wang, J., Pohlmann, T., and Xu, D. F.: The influence of meteorological variation on the upwelling system off eastern Hainan during summer 2007-2008, Ocean Dynam., 61, 717-730, 2011a.

Su, J. L.: Overview of the South China Sea circulation and its influence on the coastal physical oceanography outside the Pearl River Estuary, Cont. Shelf Res., 24, 1745-1760, 2004.

Su, N., Du, J. Z., Moore, W. S., Liu, S. M., and Zhang, J.: An examination of groundwater discharge and the associated nutrient fluxes into the estuaries of eastern Hainan Island, China using ${ }^{226}$ Ra, Sci. Total Environ., 409, 3909-3918, 2011b.

Sun, Y. J.: Application of sedimentary organic biomarkers as sources tracer and environmental change indicator: case studies in Hainan and the rivers in the east of China, Master Thesis, East China Normal University Press, Shanghai, China, 111 pp., 2011 (in Chinese with English abstract).

Tang, D. L., Kawamura, H., Lee, M. -A., and Dien, T. V.: Seasonal and spatial distribution of chlorophyll-a concentrations and water conditions in the Gulf of Tonkin, South China Sea. Remote Sens, Environ., 85, 475-483, 2003.

Thomas, S. M., Neill, C., Deegan, L. A., Krusche, A. V., Ballester, V. M., and Victoria, R. L.: Influences of land use and stream size on particulate and dissolved materials in a small Amazonian stream network, Biogeochemistry, 68, 135-151, 2004.

Tian, L. X.: Distributions of organic carbon in the East China Sea, Yellow Sea, northeastern Hainan Rivers and coasts, Master Thesis, East China Normal University Press, Shanghai, China, 117 pp., 2009 (in Chinese with English abstract).

Tian, X. P. and Li, C. C.: The environmental disruption and transformation of Xiaohai Lagoon in Hainan, Mar. Environ. Sci., 26, 91-94, 2007 (in Chinese with English abstract).

Turner, R. E., Rabalais, N. N., Justić, D., and Dortch, Q.: Global patterns of dissolved N, P and Si in large rivers, Biogeochemistry, 64, 297-317, 2003

Unger, D., Herbeck, L. S., Li, M., Bao, H. Y., Wu, Y., Zhang, J., and Jennerjahn, T. C.: Sources, transformation and fate of particulate amino acids and hexosamines under varying hydrological regimes in the tropical Wenchang/Wenjiao Rivers and Estuary, Hainan, China, Cont. Shelf Res., 57, 44-58, 2013.

Wang, B. C., Chen, S. L., Gong, W. P., Lin, W. Q., and Xu, Y. (Eds): Development and evolution of estuarine coast in Hainan Island, Ocean Press, Beijing, China, 214 pp., 2006 (in Chinese).

Wang, D.: Westward moving typhoons and typhoon damages in the Hainan Island, Trop. Geogr., 5, 141-148, 1985 (in Chinese with English abstract).

Wang, S., Wu, K. T., and Chen, M.: Analysis for precipitation change trend of Hainan Island since 1961, J. Guangxi Meteor., 27, 24-28, 2006 (in Chinese with English abstract).

Wang, S. F., Tang, D. L., He, F. L., Fukuyo, Y., and Azanza, R. V.: Occurrences of harmful algal blooms (HABs) associated with ocean environments in the South China Sea, Hydrobiologia, 596, 79-93, 2008.

Wang, S. J., Li, C. C., and Tian, X. P.: Self-adjustment and deterioration of Xiaohai barrier-lagoon-tidal inlet system in Hainan Island, J. Oceanogr. in Taiwan Strait, 22, 248-253, 2003 (in Chinese with English abstract).
Wang, W. L., Chen, J. F., Jin, H. Y., Liu, J. D., Jin, M. M., Lu, Y., Xue, B., Li, H. L., and Wang, K.: The distribution characteristics and influence factors of some species phosphorus in waters of the Changjiang River Estuary in summer, J. Mar. Sci., 27, 32-41, 2009 (in Chinese with English abstract)

Wang, Y.: Environmental characteristics of Hainan Island coast, Mar. Geol. Lett., 18, 1-9, 2002 (in Chinese with English abstract).

Wang, Y. (Eds): Tidal inlet of Hainan Island coast, Environmental Science of China press, Beijing, China, 281 pp., 1998.

Wang, Y. H. and Li, R. Y.: Landscape ecological planning in southeast coastal zone in Hainan Island, Areal Res. Develop., 25, 103 107, 2006 (in Chinese with English abstract).

Wen, L.-S., Jiann, K.-T., and Liu, K.-K.: Seasonal variation and flux of dissolved nutrients in the Danshuei Estuary, Taiwan: a hypoxic subtropical mountain river, Estuar. Coast. Shelf S., 78, 694-704, 2008.

Xu, J., Yin, K. D., He, L., Yuan, X. C., Ho, A. Y. T., and Harrison, P. J.: Phosphorus limitation in the northern South China Sea during late summer: influence of the Pearl River, Deep-Sea Res. Pt. I, 55, 1330-1342, 2008.

Yin, K. D.: Monsoonal influence on seasonal variations in nutrients and phytoplankton biomass in coastal waters of Hong Kong in the vicinity of the Pearl River estuary, Mar. Ecol-Prog. Ser., 245, 111-122, 2002.

Yu, G. H., Lu, P. D., and Qiao, S.L.: Environmental change and management of Xiaohai Lagoon, Hainan, Mar. Geol. Lett., 18, 39-40, 2002.

Yule, C. M., Boyero, L., and Marchant, R.: Effects of sediment pollution on food webs in a tropical river (Borneo, Indonesia), Mar. Freshwater Res., 61, 204-213, 2010.

Zeng, Z. X. and Zeng, X. Z. (Eds): Physicogeography of the Hainan Island, Science Press, Beijing, China, 1989 (in Chinese).

Zhang, J., Wang, D. R., Jennerjahn, T., and Dsikowitzky, L.: LandSea interactions at the East Coast of Hainan Island, South China Sea: A Synthesis, Cont. Shelf Res., 57, 132-142, 2013.

Zhang, K. R., Song, C. Y., and Chen, Y. X.: Records and disaster assessment of Typhoon in east Hainan Island in recent 50 years, J. Anhui Agri. Sci., 38, 12880-12882, 2010 (in Chinese with English abstract)

Zhao, H., Tang, D. L., and Wang, D. X.: Phytoplankton blooms near the Pearl River Estuary induced by Typhoon Nuri, J. Geophys. Res., 114, C12027, doi:10.1029/2009JC005384, 2009.

Zheng, G. M. and Tang, D. L.: Offshore and nearshore chlorophyll increases induced by typhoon winds and subsequent terrestrial rainwater runoff, Mar. Ecol-Prog. Ser., 333, 61-74, 2007.

Zhou, Z. G.: Mangrove system and development of Hainan Island. Ocean Develop, Manag., 4, 51-53, 2004.

Zhu, D. K., Yin, Y., and Martini, I. P.: Geomorphology of the Boao coastal system and potential effects of human activities-Hainan Island, South China, J. Geogr. Sci., 15, 187-198, 2005. 